\title{
PUBLIC SCHOOL FINANCE IN A GENERAL EQUILIBRIUM TIEBOUT WORLD: EQUALIZATION PROGRAMS, PEER EFFECTS AND PRIVATE SCHOOL VOUCHERS
}

Thomas J. Nechyba

Working Paper 5642

\author{
NATIONAL BUREAU OF ECONOMIC RESEARCH \\ 1050 Massachusetts Avenue \\ Cambridge, MA 02138 \\ June 1996
}

I am grateful for the very able research assistance by Randy Reback and especially Robert McMillan, as well as the financial support from the Center of Economic Policy Research (CEPR) at Stanford University. The paper is part of the NBER's research program in Public Economics and has benefitted from comments and discussions by participants of the 1995 NBER Summer Institute session on School Finance, the 1996 Winter Econometric Society Meetings, the 1996 Public Choice Society Meetings, and seminars at Washington University in St. Louis, the University of Kentucky, the University of Michigan, Michigan State University and the University of California at Santa Barbara. All remaining errors are, of course, mine. Any opinions expressed are those of the author and not those of the National Bureau of Economic Research.

(C) 1996 by Thomas J. Nechyba. All rights reserved. Short sections of text, not to exceed two paragraphs, may be quoted without explicit permission provided that full credit, including (C) notice, is given to the source. 


\title{
PUBLIC SCHOOL FINANCE IN A GENERAL \\ EQUILIBRIUM TIEBOUT WORLD: \\ EQUALIZATION PROGRAMS, PEER \\ EFFECTS AND PRIVATE SCHOOL VOUCHERS
}

\begin{abstract}
This paper uses computable general equilibrium simulations to investigate the effect of private school vouchers. It improves on past computational approaches by (i) endogenizing the funding of public schools through the modelling of an explicit political process at the school district level; (ii) embedding the private/public school choice in a Tiebout model in which agents also choose between communities that provide different public school/property tax packages; and (iii) allowing for a variety of different public school financing mechanisms ranging from purely local financing and control all the way to pure state funding. While voucher programs are shown to increase school-based stratification of agents, they tend to decrease residence-based stratification. This implies that untargeted vouchers may be equity-enhancing under some institutional settings even when there are no direct improvements in public school efficiency from increased competition. Furthermore, the effects of targeting vouchers to low income districts may not differ significantly from the effects of untargeted voucher plans.
\end{abstract}

Thomas J. Nechyba

Department of Economics

Stanford University Stanford, CA 94305-6072

and NBER 


\section{Introduction}

Increasingly frustrated with the perceived low quality of government-provided education, many states and localities are looking to the market for solutions. As a result, private school voucher experiments are under way in Minnesota and Wisconsin; school choice advocates hold state superintendent positions in many states including Arizona, Georgia and California; and governors and state legislators are increasingly making vouchers a theme of their campaigns. ${ }^{1} \mathrm{At}$ the same time, however, unease over the equity implications of introducing an increased degree of private school competition persists and has contributed to defeats of voucher proposals in several legislatures as well as in a recent California referendum. While both sides of the debate seem to generally accept Friedman's $(1955,1962)$ argument that vouchers might result in more efficient use of public resources in schools, they disagree whether this improvement is likely to be substantial enough to offset expected equity losses resulting from the loss of highly motivated students to private schools, in particular for students who remain in low income public schools.

Largely because voucher experiments have been small in scale and relatively recent, empirical evidence in this debate is still quite scarce. While recent work by Hoxby (1994) suggests we should expect substantial improvements in public school performance under increased competition, Grosskopf, Hayes, Taylor and Weber (1995) find only weak support for this proposition when performance is measured by the degree of inefficiency. Neither of these studies, however, is able to use data involving private school vouchers. Rather, they rely on current public and private school data and either speculate or leave the reader to speculate about possible effects from increased competition through vouchers. ${ }^{2}$ Thus, even if the empirical literature on school competition were to agree on the expected magnitude of the efficiency-enhancing effects of increased competition, it would, until data from such experiments becomes available, be difficult to quantitatively predict the impact of large scale public policy experiments that have never been tried.

In the meantime, the complexity of the issues involved and the ambiguity over the size of

1 There have also been private voucher initiatives in several US cities. For an early progress report on these, see Moe (1995).

2 Hoxby (1994) uses an instrumental variables strategy to assess the impact of exogenous variations in Catholic School competition on test scores, educational attainment and wages, while Grosskopf et. al. (1995) use data on Texas public school districts and an input distance function model to find strong evidence of inefficiencies in public schools but weak support for the proposition that the degree of competition is related to these inefficiencies. 
opposing effects have made meaningful theoretical work on the topic nearly impossible. ${ }^{3}$ This has led several researchers in the direction of constructing plausible computational models of education markets, calibrating them to available data, and simulating the effects of simple voucher proposals. While these models obviously must abstract from many real world features, they can give indications of the direction and magnitudes of voucher-induced changes in public and private education in a way that is impossible to do through either ordinary theoretical or empirical work. Two recent examples of this approach are represented by the important models in Epple and Romano (1996) and Manski (1992) on whose insights we seek to build. ${ }^{4}$

\subsection{Simulation Models of Private School Vouchers}

Epple and Romano assume there are no efficiency-enhancing effects of competition on public schools in order to focus on the equity and efficiency implications of a voucher system in the worst case scenario that such beneficial competitive effects do not exist. Their assumption of a passive open enrollment public school sector implies that educational quality is the same in each public school, which means that the public sector can be treated as a single school. Private schools, on the other hand, maximize profits subject to providing students with their maximum utility obtainable elsewhere. Furthermore, private schools are able to observe the ability type of each student and discriminate between students by charging differential tuition. It is immediate in this framework that all public schools must be of lower quality than every private school. 5 Furthermore, stratification occurs along two dimensions: all else equal, the public school system absorbs only the relatively low income and the relatively low ability students. Private schools, as suggested by Vandenberghe (1996), "skim the cream" off the public schools and may even subsidize the tuition of low income/high ability students. ${ }^{6}$ These theoretical insights as well as additional simulation

3 For one of the few theoretical treatments, see Hoyt and Lee (1996). In this paper, the authors demonstrate that in certain environments, vouchers can produce Pareto improvements by causing lower tax rates, and that politically feasible voucher programs may have this property.

Another more macroeconomics oriented approach can be found in Glomm and Ravikumar (1995), and Femandez and Rogerson (1995) provide an interesting simulation approach to analyzing centralization of scbool finance.

5

This is true because private schools charge tuition while public schools are free.

6 This allows private schools to internalize peer group externalities through admissions and pricing policies. which is something not possible for public schools. A tentative efficiency argument in favor of private schools follows in that the introduction of free public schools eliminates the possibility of a consirained efficient allocation of students across private schools. The distribution of students across private schools in the absence of free public schools is 
results add fuel to some of the fears voiced by opponents of increased school choice. In the model, those who gain from a school choice system in the absence of beneficial competitive effects on public schools are those already in the private schools before the voucher program and some of those who switch from public to private schools, while those remaining in the public schools experience welfare losses. It should be emphasized, however, that the addition of beneficial competitive pressures on public schools may soften these adverse equity implications of the model and could, if strong enough, lead to improvements in welfare for all agents.

Contrary to Epple and Romano, Manski (1992) addresses the tradeoffs between benefits from competition and adverse peer effects on public schools more directly by comparing two extreme types of public sectors: one that is perfectly efficient (meaning that it spends all its resources on factors that directly benefit students), and another that seeks to maximize its own surplus (by splitting expenditures into spending on factors that benefit students and factors that do not benefit students) subject to the threat of students leaving the system. In both cases, the public sector is assumed (as in Epple and Romano) to act as one unitary body that receives some exogenous level of funding per pupil. Under the surplus maximizing specification, increased private school competition leads to an increase in the fraction of public school expenditures devoted to inputs benefitting students in public schools. Thus, competition directly improves public schools, a possibility not allowed for in the work by Epple and Romano in which public schools are passive. In the case of the first specification (that assumes efficient public schools to begin with), this effect, as expected, does not materialize. ${ }^{7}$

efficient if the number of schools is efficient (which is not guaranteed). However, if this number happens to be efficient, then the possibility of discrimination in private school admissions makes possible a Pareto optimum without public schools but not with them. This, of course, ignores the possibility of other externalities that arise from greater integration. Others have addressed the peer group externality issues raised by Epple and Romano as well. De Bartolome (1990) sets out a model of local governments with peer effects and demonstrates that voting/locational equilibria with heterogeneous community compositions can be inefficient because families fail to internalize the peer group externality when choosing to migrate. It is suggested that one appropriate policy response might be to use tax/subsidy programs to deal with the externality. Schwab and Oates (199I) demonstrate that, just as private schools internalize the peer group externality in Epple and Romano, more active public schools could do the same by charging low peer quality students higher taxes. While this is objectionable on equity grounds, Schwab and Oates proceed to analyze the same problem when local governments are constrained to charge equal tax rates. They show that a system of equalizing grants that compensate communities for accepting low peer quality students may be constrained efficient.

For a recent critique of the Manski paper, see Moe and Shotts (1996). In addition to pointing out the limitations of the framework used by Manski, they calculate utility levels for low income parents within the context of the mode] and find that, while utility does decrease when there are no efficiency enhancing benefits to competition, these decreases are very small compared to the large increases in utility for the same parents in the presence of those benefits. 
The results from these papers are thus, in many ways, consistent with conventional wisdom: to the extent that competition improves the public sector, low income parents in the public school system may benefit, but as these beneficial competitive effects vanish, so do the benefits to low income parents who are left with the same (efficient) public school but without the more motivated students who have left for private schools. Since the assumption is that highly motivated students improve the school, public schools become worse when competition has no efficiency enhancing effect on the operation of those schools. The characterization of the debate in the opening paragraph of this paper is therefore confirmed in the simulation literature: there seems to be a tension between the positive efficiency enhancing effects of vouchers and their possible negative equity implications. If this is correct, the desirability of vouchers then ultimately rests on the extent to which positive impacts of competition such as those found by Hoxby (1994) actually exist.

\subsection{Features of a New Model}

We will argue here that, while both of the simulation models discussed above make great contributions to our understanding of private school choice, three important elements of public schooling in US states have been left out. (For a brief illustration of the differences between our approach and previous models, see Figure 1.) First, both Manski and Epple \& Romano model the public sector as being exogenously funded on a per pupil basis when, in fact, public school spending is determined through the political interaction of voters and legislators at the state and local levels. Second, while Manski considers separately the cases of poor, middle income and wealthy communities, he does not allow for the endogenous development of public school populations within communities through the Tiebout (1956) sorting that is familiar from the local public finance literature and that seems particularly relevant in the case of education. Similarly, while Epple and Romano allow, in principle, for different public schools in different communities, they assume an open enrollment system which results in all these public schools being identical. In both models, the empirically relevant fact that individuals sort themselves into communities based in large measure on income, and thus consume different levels of public education to begin with, is left out. Finally, neither model attempts to address the differences in expected effects of vouchers 
in different political settings. Specifically, public education is financed through a variety of different mixes of state and local financing schemes ranging from purely local funding to foundation grants and district power equalization all the way to pure state funding. It could well be the case that the effect of vouchers differs under different pre-existing state policies. We therefore propose to reconsider vouchers in a model in which we relax (i) the assumed exogeneity of funding for public schools, (ii) both the assumed absence of Tiebout migration effects and the assumed existence of a homogeneous public sector, and (iii) the assumed lack of state and local interaction.

We begin by fully defining a local public goods model with multiple local governments providing different levels of local public school quality (where parental perceptions of school outputs are a function of local per pupil spending on schools and the average "peer quality" of students in that school.) Unlike Epple and Romano, however, an agent who sends his child to a particular school must reside in that school's district (i.e. no open enrollment), and, unlike Manski, we assume that agents are mobile between districts. Furthermore, we endogenize local funding for public education by assuming that local school boards are subject to political pressures in that their budget (funded through a property tax) is set by the median voter. Thus agents choose not only whether to attend public or private schools, but also, given market clearing house prices, which community to reside in and what level of funding for public education within that community to support at the ballot box.

After analyzing vouchers in the context of this purely local system of public school finance, we add a higher level government that is also actively engaged in the funding of education. In particular, we consider the effect of vouchers under three types of institutional schemes other than a purely locally funded system: (i) a system of exogenously set state foundation (block) grants financed through a state income tax; (ii) district power equalization (which is equivalent to a system of exogenously set state matching grants); and (iii) pure state funding of education in which the state median voter sets the level of spending (funded through an income tax). The first two of these preserve local control but change local policy incentives, while the third essentially removes all local control and puts the state in charge of educational funding. We will demonstrate that the effects of voucher programs depend critically on the type of current institutional setting used 
because these institutions alter the set of expected users of the vouchers as well as the political implications for public school funding.

Of course, adding these additional complexities to previous models naturally forces us to sacrifice some of these previous models' richness in other dimensions. In particular, we will allow for neither the rent seeking behavior suggested in Manski nor the complex private school pricing mechanism derived in Epple and Romano. More precisely, since it is clear from Manski's work that modelling public schools as inefficient in the absence of competition improves the equity properties of vouchers, we will assume efficiency (at least as observed by parents) of both public and private schools and thus look at worst case equity implications. Furthermore we will assume that the private school market consists of competitive, profit maximizing schools who charge a single admissions price for all students and can "cream skim" explicitly in their admissions policies. ${ }^{8}$ Finally, peer quality, is modelled more crudely than in Epple and Romano and Manski in that we assume that it is perfectly correlated with parental socio-economic status. While these are simplifications of previous models that should be kept in mind throughout our analysis, they permit us to focus on an entirely new set of issues not previously analyzed in the literature without "rediscovering" the important insights already obtained in Manski (the trade-off between adverse effects from cream skimming and positive effects from competition) and Epple and Romano (the efficiency and equity implications of price discriminating behavior by private schools.)

Section 2 proceeds to outline the model, and Section 3 comments on computational issues. Section 4 then investigates the general equilibrium effects of vouchers in a variety of institutional settings, and Section 5 ends with comments on the limitations of the model, possible extensions to the analysis and some concluding remarks.

\section{The Model}

The computable general equilibrium model developed here is calibrated to New Jersey data ${ }^{9}$

8 For reasons elaborated below, the more complicated pricing mechanism of Epple and Romano loses its intuitive appeal under our setting.

9 While we have thus made an attempt to calibrate the model to be consistent with the data, we do not take the view that the simulation results offered should be interpreted very literally. In particular, since any computational model must make a number of simplifying assumptions, we view our approach as an extension of theory that, like pure theory, can aid in developing basic intuitions concerning the nature and magnitude of various general equilibrium effects. Our focus will therefore be on general lessons learned from the analysis rather than a literal interpretation of any single set of 
and is based on the theoretical model in Nechyba (1996a) where the existence of an equilibrium without private schools is proved. 10 The model takes as given community boundaries that divide a large set of different houses into local political entities which produce public schooling funded through a property tax. An additional political unit called the state (or nation) encompasses all communities and may finance additional education programs through a state income tax. There are no a priori restrictions on the mix of house types across communities; i.e. some communities may have a fairly homogeneous housing stock while others have both "good" and "bad" houses Similarly, some communities may be inherently more preferred because of particular community qualities. The model is therefore attempting to explain neither the evolution of the housing stock nor the formation of communities. Rather, it takes these as having evolved exogenously and resulting from some given history. ${ }^{11}$ Its potentially heterogeneous intracommunity housing structure allows for the empirically important possibility of the coexistence of rich and poor sectors within a particular community, a feature not possible in models that view housing as a perfectly divisible, homogeneous good (Epple, Filimon and Romer (1993), Rose-Ackerman (1979)). Consumers in the model own both houses and some amount of the private good, both of which are tradeable at market prices, and choose their optimal place of residence given their preferences and budgets. The existence of a land market rather than housing exogenously supplied by absentee landlords (as is common in the literature (see, for example, Epple, Filimon and Romer (1993)) enables the model to seriously investigate capitalization and its impact on communities. Finally, each agent also votes on the level of local property taxation (or state income taxation in the case of a state financed public school system).

simulation numbers.

10 The sufficient conditions for the existence of an equilibrium in this model are fairly weak compared to others in the literature. They include standard assumptions on preferences and technologies without the usual single crossing conditions (Westhoff (1977), Epple, Filimon and Romer (1993)) and without Dunz's (1985) independence assumption. It is trivial to extend the existence theorem to the case of private schools as noted below. Also, in this paper we deviate from Nechyba (1996b) in that we do not explicitly model a separate state public good because it would add little to the analysis.

11 Since construction of new houses is not possible in the context of the model (and is technically extremely difficult to model (see Nechyba (1996a)), the model is most appropriate to the analysis of a relatively developed urban/suburban economy. We do not view this as a particular weakness of the approach because it is in such economies that private school competition is likely to have an effect. (Demand for private schools in remote and undeveloped rural areas is likely to be less of a factor due to the limited market size.) 


\subsection{Endowments and Preferences}

The main elements of both the general model as well as its CGE derivative are summarized formally in Table 1 . The set $\mathrm{N}$ represents both the set of agents and the set of houses in the model, where $n \in N$ is defined as that agent who is initially endowed with house $n .12$ A fixed community structure $\mathrm{C}$ is imposed on this set of houses and partitions it into a set of house types $H=\{1, \ldots, h, \ldots, \bar{h}\}$ spread over a set of communities $M=\{1, \ldots, m, \ldots, \bar{m}\} . C_{m b}$, then, is both the set of houses of type $h$ in community $m$ and the set of agents initially endowed with such houses. The CGE version presented here defines $\mathrm{N}=[0,1], \mathrm{H}=\{1,2,3\}$ and $\mathrm{M}=\{1,2,3\}$, which implies the existence of nine different house endowment types (three house types in each of three communities). Each of these is assumed to be represented in the economy in equal numbers; i.e.

$$
\mu\left(\mathrm{C}_{\mathrm{mb}}\right)=1 / 9 .
$$

In addition to his house endowment, each agent $\mathrm{n}$ is also endowed with a strictly positive amount of private good $z(\mathrm{n})$ called income. The set of income levels is assumed to be finite which gives rise to a set of income classes $I=\{1, \ldots, 1, \ldots, \bar{i})$. This implies that the house and income endowments jointly define a set of endowment types

$$
\mathrm{E}=\left\{\mathrm{E}_{\mathrm{mhi}} \mid(\mathrm{m}, \mathrm{h}, \mathrm{i}) \in \mathrm{M} \times \mathrm{H} \times \mathrm{I}\right\}
$$

where $\mathrm{e}_{\mathrm{mhi}} \in \mathrm{E}_{\mathrm{mbi}}$ is an agent that falls into the income class $\mathrm{i}$ and is endowed with a house of type $\mathrm{h}$ in community $\mathrm{m}$. Our CGE model contains five of these income classes (with incomes of 2, 3.5, $5,6.5$ and 8 roughly corresponding to New Jersey household income levels scaled by $\$ 10,000$ ). These, combined with the three house types in each of three communities, generates 45 endowment types each of which is represented equally in the economy; i.e.

$$
\mu\left(\mathrm{E}_{\mathrm{mhi}}\right)=\frac{1}{45} \quad \forall(\mathrm{m}, \mathrm{h}, \mathrm{i}) \in \mathrm{M} \times \mathrm{H} \times \mathrm{I}^{13}
$$

Finally, agents are endowed with a utility function $u^{\mathrm{n}}: \mathrm{M} \times \mathrm{H} \times R_{+}^{2} \rightarrow R_{+}$which takes as its arguments the community and house type the agent lives in, private good consumption $\mathrm{z} \in R_{+}$, and

12 More precisely, the set of houses and consumers is defined as part of a measure space $(N, \mathcal{N}, \mu)$ where $\mu$ is taken to be the Lebesgue measure. All subsets referred to are henceforth assumed to be measurable.

13 Some have suggested that this uniform distribution of income is not entirely realistic. While this is true, we refer the reader to footnote 9 which notes that we do not view the calibration of the model as an important feature of the analysis. The effect of a skewed distribution of income on local versus state voting outcomes has been treated effectively in Sonstelie and Silva (1995). Furthermore, we note that, despite the frequent use of the term "high income agents" later in the paper, this is very much a model of middle income communities (given top incomes of $\$ 80,000$ ). 
a perceived school quality level $s \in R_{+}$. In the CGE version, all agents have the same utility function which is defined as follows: 14

$$
u^{\mathrm{n}}(\mathrm{m}, \mathrm{h}, \mathrm{s}, \mathrm{c})=\mathrm{k}_{\mathrm{mh}} \mathrm{s}^{\beta_{\mathrm{c}} \gamma} \quad \forall \mathrm{n} \in \mathrm{N} .15
$$

where $(\mathrm{m}, \mathrm{h})$ is the community and house type of residence, $\mathrm{s}$ is their school's quality and $\mathrm{c}$ is their private good consumption.

\subsection{Parental Perceptions of School Quality}

The inclusion of school quality rather than student achievement in the utility function deserves some attention. As suggested by the household production function literature (Becker (1991)), school quality is only one of the inputs in the production of student achievement. The other, parental commitment of time and resources, plays a major role as well (Hanushek (1986)). While parents therefore care directly about student achievement (where achievement as defined by parents may entail substantially more than good test scores), they care about school quality only indirectly as one of the inputs required in the production process of this achievement. Thus, the utility function in (4) is somewhat "reduced form" in nature because school quality rather than student achievement enters directly as an argument. ${ }^{16}$ This is done for simplicity and, while it is

14 As demonstrated in Nechyba (1996a), there is no technical problem in including spillovers or population externalities in the model. We comment on the effect of such externalities on our results in Section 5.

15 This utility function satisfies all conditions necessary for the existence of an equilibrium (Nechyba (1996a)). The parameters are set to be consistent with New Jersey micro tax data in Nechyba (1996c). Preferences are assumed to be identical not only for computational convenience but also because stratification results in Nechyba (1996a) imply that under these conditions, the equilibrium assignment of agents into house types is unique. Finally, we should note that the CGE model described in Necbyba $(1996 \mathrm{~b}, \mathrm{c})$ contains an additional state public good financed by a state income tax. This feature has been "turned off" for the present exercise because it is not relevant to the issues discussed in this paper.

16 We can think, for example, of the following simple motivating example for this reduced form: Suppose each agent has a utility function of the form $u\left(\{, a, c)=\mathscr{C}_{\mathrm{a}^{\beta}} \mathrm{c}^{\gamma}\right.$ where $l$ is parental leisure, $a$ is the child's achievement and $c$ is parental consumption. In order to avoid a direct labor/leisure choice (which is not part of our model), suppose that income $z$ is exogenous (perhaps the result of a 40-hour workweek), and that parents are endowed with 1 unit of leisure (which cannot be used for working; i.e. there is no overtime.) Further, let us abstract for this illustration from the Tiebout model in the text and assume that any level of school quality s can be purchased on the market at price p per unit and that the child's achievement level $a$ is determined by $a=s^{\delta} x^{(1-\delta)}$ where $x$ is the amount of leisure parents spend on their child's education at home. Parents then solve the following maximization problem:

$$
\max _{\mathbf{X}, \mathrm{s}} u(\zeta \mathrm{a}, \mathrm{c})=F \mathrm{a}^{\natural} \mathrm{c}^{\gamma} \text { subject to } \quad \begin{aligned}
\mathrm{c} & =\mathrm{z}-\mathrm{ps} \\
\mathrm{a} & =\mathrm{s}^{\delta} \mathrm{x}^{(1-\delta)} \\
l & =1-\mathrm{x} .
\end{aligned}
$$

The optimum occurs at $s=\frac{\beta \delta z}{(\gamma+\beta \delta) p}$ and $x=\frac{\beta(1-\delta)}{(\alpha+\beta(1-\delta))}$ which implies $c=\frac{\gamma z}{(\gamma+\beta \delta)}$. This result is equivalent to the result of a reduced form utility maximization problem in which parental inputs are ignored and parents care directly 
usually not acknowledged explicitly, is standard in the entire literature cited in the introduction. It is important, however, to recognize that the school quality argument in the utility function represents school quality as defined and perceived by parents. While the education production function literature reviewed by Hanushek (1986) is still unclear as to what school inputs matter in determining test scores, school quality (and student achievement) more broadly defined may include other aspects of schools (music classes, athletic activities, etc.) that have little relation to test scores themselves but that may nevertheless be important to parents. ${ }^{17}$

This parentally defined school quality is provided by local governments (and in a later version by the state government) as well as private institutions, and we assume that both private and public school quality is judged by parents as if it resulted from a production process that uses as inputs both per pupil spending and the peer quality in the school (as measured by per capita income of parents). If per pupil spending in the school is $Z_{s}$ and average peer quality is $P_{s}$, we define the perceived school quality as

$$
s=f_{\mathrm{s}}\left(\mathrm{Z}_{\mathrm{s}}, \mathrm{P}_{\mathrm{s}}\right)=\mathrm{Z}_{\mathrm{s}}^{(\mathrm{I}-\mathrm{\rho})} \mathrm{P}_{\mathrm{s}}^{\mathrm{\rho}}, 18
$$

where $\rho \in R_{+}$is a parameter indicating the strength of the peer effect parents perceive. Thus, if $\rho=0$, only spending matters to parents, while if $\rho=1$, only peer effects matter. Furthermore, we define $P_{s}=I_{s} / 15$ (where $I_{s}$ is the average income of parents who send their children to the school in question) to make peer values roughly equal in order of magnitude to per pupil spending, which then allows us to more easily interpret different values of $\rho$. (For example, $\rho=0.5$ can then be interpreted to mean that parents place roughly equal value on peer effects and spending.)

about school quality; i.e. the outcome is equivalent to

$$
\max _{\mathrm{s}} u(s, c)=\mathrm{s}^{\lambda} \mathrm{c}^{(1-\lambda)} \text { subject to } \quad \mathrm{c}=\mathrm{z}-\mathrm{ps}
$$

when $\lambda=\frac{\beta \delta}{(\gamma+\beta \delta)}$. While this still circumvents issues related to endogenous labor/leisure choices, it illustrates the general motivation for viewing school quality as a reduced form argument that enters directly into utility functions.

It could, for example, be that spending really does not matter very much in determining test scores because lower spending is replaced by increased parental inputs; i.e. parents purchase private music lessons when schools no longer fund them, or parents are more vigilant in monitoring homework progress as student/teacher ratios rise. In that case, parents may care about spending despite the empirical observation that spending is not correlated with test scores. Empirical evidence to the effect that parents provide less effort as schools improve can be found in Houtenville (1996).

18 Note that we assume that parents act as if there was this underlying production process. An alternative interpretation is to think of parents simply caring about peer quality and spending without actually having an underlying production process in mind; i.e. all else equal, parents simply desire to have high income peers for their children. (We have also attempted to use other CES production functions. Since results do not change qualitatively they go unreported bere.) 
Again, we take no position in this paper on either the "proper" definition of school quality or the "true" level of $\rho$. We do, however, argue that the empirical evidence suggests strongly a definition of school quality by parents that makes the perceived level of $\rho$ significantly less than 1; that is, the fact that parents in different school districts choose to spend dramatically different amounts on education, and the fact that educational spending is such a strong focus in court battles implies that parents must believe spending to be an important input to the production process of school quality as they define it. If they did not, all communities would spend the minimum amount necessary to run a public school. We therefore do not consider cases where $\rho=1$ in this paper, but we do allow for the possibility that parental perceptions are wrong, and that the true $\rho$ is actually equal to 1 (i.e., spending does not matter.) For this reason, we report not only the parentally perceived quality level in our simulation results, but also the level of per pupil spending on education and the peer quality level for each community. The only factor that matters for parental choices, however, is the perceived $\rho$ and the resulting perceived definition of quality.

Finally, we note in passing that our specification of peer effects is consistent with the general empirical findings in Henderson, Mieszkowski and Sauvageau (1978) in that they are modelled as equally important for high income and low income students. ${ }^{19}$

I9 We chose this fairly primitive specification of peer effects after attempting to learn the true nature of peer effects from the empirical literature. First highlighted in the Coleman Report (1966), peer effects have long been thought to play a vital role in education. Summers and Wolfe (1977), using pupil specific evidence from Philadelphia, find evidence to confirm the Coleman finding that less able students benefit from more able peers while high ability students are little affected by peers (which contrasts with our specification in which peer effects are equal for all students). Henderson, Mieszkowski and Sauvageau (1978), bowever, while documenting strong evidence for peer effects among French speaking Canadian students, find that these peer effects are equally present for both high and low ability students, consistent with our specification. In an important recent paper, Evans, Oates and Schwab (1992) cast doubt on all these results by demonstrating that, in the case of teenage pregnancy and school dropout behavior, strong peer effects are found with standard regressions but vanish when endogeneity problems are addressed. This suggests that past results on peer effects may be very much overstated. Link and Mulligan (1991) paint a very complex picture of peer effects along both ability and racial lines and find that some groups (in particular blacks) benefit from having others in that group in the class room. As is well known, the education production function literature is similarly littered with contradictory evidence (Hanushek (1986)), but recent cross country examinations have provided further evidence that peer effects of the kind we model may be quite important (Toma (1996)). As a result of these ambiguous findings, theoretical models typically pick a somewhat simple specification of peer effects that is consistent with some past empirical measurements (Brueckner and Lee (1989), Arnott and Rowse (1987)). For a good summary of general theoretical existence and welfare theorems in models with arbitrary population externalities, see Scotchmer (1994), and for an excellent demonstration of the empirical difficulties involved in measuring peer effects, see Manski (1993). 


\subsection{The Local Public Sector}

Local public schools are funded through proportional property taxes set in accordance with majority rule voting by local residents, and we assume that only residents within a community can attend that community's public school. Voters are assumed to be myopic in the sense that they take community compositions, property values and their choice of private or public schooling as given when they go to the polls. (Voter myopia is a relatively standard assumption in the literature (see Epple, Filimon and Romer (1993), Dunz (1986), Rose-Ackerman (1979)) and is inconsistent only out of equilibrium. $)^{20}$ Since local budgets have to balance, the relationship between $t_{m}$, the local tax rate, and $s_{m}$, the perceived public school quality in community $m$, is one to one and given by

$$
s_{\mathrm{m}}=\left(\frac{\mathrm{t}_{\mathrm{m}} p\left(\mathrm{C}_{\mathrm{m}}\right)}{\mu\left(\text { student }_{\mathrm{m}}\right)}\right)^{(1-\rho)}\left(\frac{\mathrm{I}_{\mathrm{s}}}{15}\right)^{\rho}
$$

where $p\left(\mathrm{C}_{\mathrm{m}}\right)=\sum_{\mathrm{h} \in \mathbf{H}}\left(\mu\left(\mathrm{C}_{\mathrm{mb}}\right) \tilde{p}\left(\mathrm{C}_{\mathrm{mb}}\right)\right)$ is the local property tax base. This base varies with the endogenously determined house price function $\tilde{p}: \mathrm{M} \times \mathrm{H} \rightarrow R_{+}$that gives rise to a house price vector $\mathrm{p} \in R_{+}^{\bar{m}} \overline{\bar{h}}$; i.e. the function $\widetilde{p}$ assigns a unique price to each house type in each jurisdiction. (The first term is simply per pupil spending in the public school in community $m$.) This, combined with myopic voting and standard assumptions on preferences, is shown in Nechyba (1996a) to yield single peaked preferences over local school spending levels (or, equivalently, over local property tax rates) which in turn implies the existence of local voting equilibria. 21

Agents are also assumed to be myopic in their location decisions in that they take prices, other public good levels and other agents' locations as given. They do not, however, take their choice of public versus private school as given when they make their migration choices; that is, when determining their maximal utility in each potential place of residence, they consider both the case of attending private and the case of attending public schools.

20 This is because all expectations implicitly held by myopic voters are fulfilled in equilibrium when voters vote holding levels of public goods, community compositions and property values fixed at the actual equilibrium values. Thus, in equilibrium, voters correctly take current levels of these variables into account. Myopic voting of this kind is essential for the theoretical work underlying these simulations; without it, we would not be able to make the statements regarding existence and "uniqueness" of equilibria below that seem to us as important underpinnings for our methodological approach.

21 Note that we avoid the Stiglitz (1974) non-single peakedness problem by assuming that individuals vote on local public schools holding fixed their choice over public versus private schools. Thus, if the voter bas chosen a private school, his ideal point is a local tax rate of zero and bis preferences are single peaked. If, on the other hand, the voter has chosen the public system, his preferences are single peaked as demonstrated in Nechyba (1996a). 


\subsection{Other Institutional Settings}

Thus far we have defined the local public sector under a system of pure local public finance via the property tax. We will also consider other financing mechanisms of public schools. In particular, we will discuss the effect of private school vouchers under a state foundation grant system, a district power equalization system and a pure state financed system. ${ }^{22}$ We will discuss these in more detail in Section 4. For now, we simply note that foundation grants are per pupil block grants to local governments who are obligated to spend them on public education and have the discretion to raise additional funds for local public schools through a local property tax (set in accordance with majority rule). The block grants are funded by the state government through a proportional state income tax. District power equalization, on the other hand, is a system of matching grants with a negative match rate for high tax base districts and positive matching rates for low tax base districts. The intent of the program is to insure that equal tax rates imply equal spending levels across communities, and we will assume that the program is revenue neutral; i.e. the revenues raised from the negative match rates on high base communities is exactly sufficient to cover the positive matching grants to poor communities. Therefore no additional state income tax revenues are necessary, and local property tax rates continue to be set by the median voter. Finally, a pure state funded system involves no local property taxes and only a proportional state income tax whose rate is set by the median voter in the state.

\subsection{Private Schools}

Finally, with no clear guidance from the empirical literature as to the appropriate objective functions of private schools, we assume that private schools are small, competitive and profitmaximizing institutions that each set a single tuition level (equal, due to the zero profit condition, to per pupil spending in that school) as well as a minimum peer quality standard below which they will not admit any students. Since we allow private schools to be relatively small, we are implicitly assuming that all scale effects are exhausted relatively early. ${ }^{23}$ Furthermore, we implicitly assume

22 For technical definitions of these programs, see Nechyba (1996b).

23 There is little empirical evidence to support large economies of scale for schools beyond a few hundred students. Dewey, Husted and Kenny (1995), for example, find no support for this. 
away the type of price discriminating behavior derived in Epple and Romano where private schools subsidize high peer quality children. While we think such behavior on the part of private schools is reasonable under the assumptions in Epple and Romano, it strikes us as unreasonable in the context of our model. More specifically, since we have made the simplifying assumption that peer quality is perfectly correlated with income, the price discriminating behavior in Epple and Romano would imply regressive tuition structures. ${ }^{24} \mathrm{We}$ consider this an empirically unlikely outcome, especially in the presence of voucher systems that are likely to be implemented in a political environment that would explicitly prohibit such price discrimination. Our model therefore results in a private sector in which each private school is completely homogeneous; that is, each private school, if it has positive enrollment, has students of only the minimum peer quality (because higher quality peers have their own private schools) and charges tuition equal to the most preferred level of tuition for that peer group (because if a different level of tuition were charged, a new entrant could make positive profits and attract all students to his school with a different tuition level). ${ }^{25}$

\subsection{Definition, Existence and "Uniqueness" of Equilibria}

An equilibrium under some arbitrary state program $\mathrm{x}$ (where $\mathrm{x}$ could be a system of foundation grants, district power equalization, or vouchers) is defined as follows:

24 We should further note that implementing Epple and Romano's differential pricing scheme in a model with multiple communities (such as ours) would be technically extremely challenging.

25 This logic is similar to Hamilton's (1975) familiar zoning argument in which communities (rather than private schools) fix a local tax/spending package (analogous to tuition levels) and set a minimum zoning requirement (analogous to our minimum peer quality). In the course of our analysis, we have also investigated two other private school market assumptions:

1. A single non-profit private school that seeks to maximize enrollment. (This is similar to one of Manski's specifications.)

2. A single non-profit, cream skimming private school that seeks to maximize enrollment subject to not accepting students below a certain "peer quality".

We have foregone reporting results under these assumptions for several reasons: (i) additional tecbnical problems arise that complicate the analysis; (ii) results are qualitatively similar but more difficult to interpret; and (iii) most importantly, we do not view either of the above assumptions as plausible in equilibria in which private schools can differentiate on the basis of peer qualities. More precisely, under both these assumptions, another private school could arise and make positive profits by catering to certain peer groups. This competitive process then leads to the outcome we assume in the body of the paper that many private schools who cater to each type will arise. In such an environment, each school charges the optimal tuition for the members of the type they are serving-Unless schools can find a way of mixing individuals of different types within one school, there is no way to break this equilibrium. The only such tool would involve price discrimination which, we argue in the text, is unlikely to arise and is politically infeasible in a model such as ours. 
Definition: An equilibrium $\left(J, p, t, x, s, s^{p}\right)$ under state program $x$ is a list of population assignments to communities $\mathrm{J}$, prices $\mathrm{p} \in R_{+}^{\mathrm{MH}}$, tax rates $\mathrm{t} \in R_{+}^{\mathrm{M}}$, local public school quality levels $\mathrm{s} \in R_{+}^{\mathrm{M}}$, and private school quality levels $\mathrm{s}^{\mathrm{P}} \in R_{+}^{45}$ (there are 45 types) such that: 26

(i) prices clear the market; i.e. there is no excess demand or supply for any house;

(ii) all local government budgets balance;

(iii) consumers cannot gain utility by moving and/or changing schools;

(iv) local property tax rates are determined through majority rule;

(v) if positive, private school spending in each school is equal to the most preferred spending level by its homogeneous customers;

(iv) any net costs the state government incurs under state program $\mathrm{x}$ must be fully financed through a proportional state income tax. 27

As noted already, Nechyba (1996a) proved the existence of equilibria in the presence of peer effects (spillovers) when there are no private schools. Extending the mere existence result to the case of private schools is trivial: simply assume that there are no public schools. In that case, everyone attends a private school and votes for zero spending on public schools (given that they have chosen private schools). Existence of this new but trivial equilibrium can be shown by the same methods as employed in Nechyba (1996a). Similar somewhat less trivial equilibria in which a subset of the local communities provide no public education can be shown to exist. However, the interesting type of equilibrium in this model is one that generates, under certain policies, a mix of public and private education in each community. The stratification results in Nechyba (1996a) suggest that, when preferences are identical and communities are sufficiently different in their inherent desirability (i.e. when utility functions are identical and the $\mathrm{k}_{\mathrm{mh}}$ 's in those utility functions are sufficiently different as in this model), the partition of agents into communities in the presence

26 Note that $\mathrm{J}=\left(\mathrm{J}_{\mathrm{mh}} \subset \mathrm{N} \mid \mu\left(\mathrm{J}_{\mathrm{mh}}\right)=\mu\left(\mathrm{C}_{\mathbf{m b}}\right) \forall(\mathrm{m}, \mathrm{h}) \in \mathrm{M} \times \mathrm{H}\right\}$ and $\mathrm{C}$ are both partitions of $\mathrm{N}$. The difference, however, is that $\mathrm{C}$ assigns houses (and the initial distribution of agents) to house types and communities, while $J$ gives the equilibrium assignment of agents to houses and communities. For a more formal definition of both an economy and an equilibrium, see Nechyba (1996a).

27 We also use an analogous equilibrium concept for the last case considered in this paper in which local governments no longer fund public education but rather the state government takes over this funding. In that case, condition (ii) changes to read "the state budget must balance", and condition (iv) reads "the state income tax rate is determined through majority rule voting." 
of public schools in all communities is unique up to a transformation of prices. ${ }^{28}$ The computable model in this paper attempts to find this equilibrium and only when it cannot, resorts to the least trivial equilibrium (i.e. the equilibrium under which the fewest possible number of communities have no public school.) As we will see, however, under some policies, no equilibria with public schools in every community exist.

\subsection{Calibration of the Model}

The utility function in the model is parameterized to be consistent with data from several school districts in Camden County, New Jersey. Other parameters, such as endowments and community sizes were arbitrarily fixed. The calibration described here is therefore "partial" in the sense that, while parameter values are picked to be consistent with data, the benchmark equilibria reported in Table 2 are computed (and then observed to be consistent with the data). Due to space considerations, the specifics of this parameterization are not reported here (see Nechyba (1996c)). We do note, however, that the model must be re-parameterized for different assumed values of $\rho$ in the perceived education production process; i.e. in order to keep public school spending levels consistent with the data, $\beta * \rho$ must be constant, which means that $\beta$ must be adjusted as our assumptions about $\rho$ change. Finally, we refer the reader to footnote 9 which cautions against overinterpreting any specific set of simulation numbers.

\section{Computation of and Characteristics of Equilibria}

Each simulation begins with the number of private schools set to zero and calculates the "public school benchmark equilibrium"without private schools. (This process is illustrated in Figure 2). The CGE program to calculate these benchmark equilibria begins with the information contained in Table 1 as well as a vector of initial house prices. It iterates to an equilibrium by first finding local election outcomes, then determining equilibrium prices given those outcomes, before using those prices (and the new community compositions) to update election results, and so forth. 29

28 Due to the discreteness of the house types, however, prices themselves may vary within small intervals, as may local public good levels. The computer program picks the first equilibrium price vector within those intervals that it finds. Simulation tests have shown these intervals to be quite narrow. Furthermore, simulation tests indicate that the inherent differences across communities (the $k_{\operatorname{mh}}$ 's) are sufficiently different to yield uniqueness of the equilibrium partition of agents.

29 The program is written in GAMS (General Algebraic Manipulation System). 
More precisely, the program uses the initial data in Table 1 to identify each community's median voter who takes prices and everyone's location as given. That voter's optimal choice determines the community's school spending level (and local property tax rate) which, combined with the endogenously determined peer level, determines the perceived public school output level. Given these election results, the program iterates to find equilibrium property values. In particular, during every iteration, each agent's optimal location at the current prices is determined, and these prices are adjusted upward (by a small fixed amount) if the house type in question was in excess demand during this and the past iteration and downward (by the same amount) if it was in excess supply during these iterations. If a particular house type alternated between being in excess demand and excess supply, the previous two prices are averaged. This process, while not guaranteed to converge, typically does converge within twenty iterations. Once equilibrium prices have been found, i.e. once excess demands for all houses are zero, the program starts over with a new major iteration by identifying median voters in the new community populations. The process continues until the perceived school output levels, the local tax rates and the prices have converged. Throughout the process, the value of each agent's initial house endowment is used to determine that agent's budget. Values typically converge within several major iterations and are only slightly sensitive to initial prices (subject to scaling).

The public school benchmark equilibrium without governmental interaction is presented in Table 2 with $\rho=0.0$ (i.e. for the case when parents care only about school spending). School spending levels (equal to perceived school output levels in this case) can be interpreted as per pupil spending by local governments. The school spending figures fall within the actual range of per pupil spending on education (roughly between $\$ 2500$ and $\$ 5000$ ) for Camden County in 1987 (for which the model was calibrated). Agents separate into low, middle, and high income communities, but there is some overlap due to overlapping values of the $\mathrm{k}_{\mathrm{mh}}$ 's (see Table 1). Higher income communities tend to have higher school spending levels and lower property tax rates, and property values (the value of yearly housing services) tend to increase in community wealth. The fact that property values are inversely related to property taxes in Table 2 is simply due to the fact that property in community 3 is inherently (i.e. all else being equal) more desirable than property in 
community 2 which again is inherently more desirable than property in community 1 . (This is reflected in the different values of $\mathrm{k}_{\mathrm{mh}}$ as reported in Table 1.) ${ }^{30}$

Note that the only feature of Table 2 that is exogenous is the sum of the entries in the "Income" column. Each entry in that column represents the average household income within that community. Since the average income endowment (see Table 1) is 5, the average of the entries in the income column will always be equal to 5. Everything else in the table is endogenous. "Wealth" is defined as the community average of individual incomes from both private good endowments and property endowments; "Property" is the average house value in the community; "Prop. Tax" is the tax rate on the yearly housing services in the community; "School" is the parentally perceived level of school quality (as defined in equation (5)); "LPSpend" is per pupil spending in local public schools; "LPeer" is the peer quality level in the local public school; and "\%Private" is the fraction of parents sending their children to private schools. (In later simulation tables, "PrPeer" is the average peer quality level of children attending private schools.) All dollar values are scaled by $\$ 10,000$.

So far, the benchmark equilibrium does not include private schools. Once the public school equilibrium (of the kind presented thus far) is determined through the algorithm described in Figure 2 , we proceed to calculate the actual equilibrium with private schools from this public school benchmark. This process is illustrated in Figure 3. More precisely, we determine each type's most preferred private school tuition level under our assumption that private schools perfectly discriminate between different peer quality types, taking as given the present location of all agents as well as all prices, taxes and public school levels. By comparing each agent's utility under local public school consumption to his utility under the new private school option, we determine whether he is a private or public school consumer. We then recalculate voting outcomes (by assuming that private school attendees have single peaked preferences over public school levels

30 It has been suggested that, were entrepreneurs to enter the model, they would choose to build houses solely in community 3 because of the bigher property values. This is not necessarily the case. Property values here can be thought of as the value of both the land the houses are built on and the houses themselves. They are higher in community 3 than elsewhere because (i) land may be inherently more desirable in community 3 (scenery, lakes, trees, etc.) and (ii) a house of type $i$ in community 3 may be bigger and better than a bouse of type $i$ in other communities. (The fact that houses in all three communities are labeled 1,2 and 3 should not necessarily be interpreted to mean that a house of type $i$ in community $m$ is identical to a house of type $i$ in community $m$ '. These differences could be due to exogenous phenomena such as zoning.) Thus, entrepreneurs would not automatically choose to build in community 3 : while property values are higher, so are land costs and house construction. The fact that houses are extraordinarily expensive in Beverly Hills, for example, does not imply that entrepreneurs will build new houses only in Beverly Hills. 
with peak at zero spending). Given these outcomes as well as prices, consumers then choose their most preferred location and public/private school simultaneously, and prices adjust until supply equals demand. Then a new iteration begins with a new voting stage, a new price adjustment phase, etc. until the process converges (usually within a few iterations). In many cases, such as in the benchmark case reported in Table 2, the addition of the private school option does not change the initial benchmark equilibrium, and no private schools arise. In this case, only one iteration in Figure 3 occurs and simply gives confirmation that the public school benchmark equilibrium is in fact also an actual equilibrium with the potential for private schools. The reason no private school arises for the benchmark public school equilibrium when $\rho=0$ (Table 2) is that, in the absence of peer effects, disagreements within communities concerning the level of public school spending are not sufficiently large to induce anyone to choose to opt out and pay his most preferred private school tuition. 31

Under higher peer effects, we might expect a larger propensity of high income/high peer quality types to opt out of the public school system. This is, in fact, precisely what happens. Table 3 shows both the Public School Benchmark Equilibrium (i.e. the output from the process in Figure 1) as well as the Actual Equilibrium (with private schools). Note that the former is considerably more stratified than the equilibrium in Table 2 where $\rho$ was set to 0 rather than 0.5 . This is an observation that will, ceteris paribus, hold throughout the simulation results we present in this paper: In the absence of private schools, increased perceived peer effects lead to larger residential stratification of agents based on income and wealth, more stratified property values as well as more stratified public outcomes. When we allow for the existence of private schools, however, as peer effects get large, private schools appear in low income communities (see Table 3(b)). Furthermore, these private schools decrease the level of residential stratification as high income residents find it advantageous to settle in low income neighborhoods (to avoid house payments in

31 The reader may express some initial skepticism at this point because the model so far predicts no private schools while we do observe private schools in the real world. We have three comments in this regard: (i) If peer effects were larger, as we will see shortly, we would see very high income individuals form private schools. (ii) If some individuals have strong preferences for private (perbaps religious) education, our framework would predict the private schools to arise even in the absence of peer effects (see Long and Toma (1988)). (iii) The current model looks at moderate to middle income households earning between $\$ 20,000$ and $\$ 80,000$. The absence of substantially wealthier individuals is in part responsible for the lack of interest in any private school in the absence of peer effects (see Schmidt (1992)). Our suspicion is that private school enrollments in the presence of Tiebout stratification are primarily due to inherent preferences for some particular form of private (especially religious) education as well as the presence of very high income families. These types of individuals are not the focus of the present analysis. 
high income neighborhoods that capitalize good public schools) and attend private schools. Thus, while community l's average income is substantially higher due to these different location patterns caused by the private school, the increase in peer group effects in that community's public school is small in comparison (and uncharacteristic of the rest of the simulation results reported below. ${ }^{32}$ ) The peer level in the private school, however, is 0.5333 which indicates that the average parental income of students attending that school is 8 (0.5333 times 15) which is the highest income of any agent in the model. Thus, private schools are occupied by high income agents who reside in low income communities in order to take advantage of private schools. The perceived public school quality, however, rises not because of the small increase in the peer quality in community 1's public school, but more because of increased per pupil spending on public education. This increase occurs as more local funds per pupil are available due to lower public school enrollment in community 1 and as those attending private schools pay a disproportionately large share of local taxes (because they reside in the best houses) while not consuming any of the locally provided public education. (The fact that the private school attendees now vote for zero public school spending does not change the median voter result sufficiently to offset the former positive impact on per pupil spending.)

In moving from the equilibrium without private schools (Table 3(a)) to the equilibrium with private schools (Table 3(b)), the migration of high income residents comes from the middle income community. Thus, while we see an increase in all variables in the poorest community as a result of the migration, the middle income community suffers from lower property values as well as decreased spending and peer effects in its public school. Community 3, on the other hand, remains largely unaffected as its high income residents are still sufficiently satisfied with their public schools. As we show in the next table, however, as peer effects rise further, private schools show an increasing presence in all three communities.

In Table 4, we report average community variables for levels of $\rho$ ranging from 0 to 0.7 . (As

32 As demonstrated below, the introduction of private schools more commonly leads to a decline in peer quality in low income public schools. The small increase in peer quality here is due to capitalization effects that increased the total income of a small low income segment of the population (that is endowed with community $1 /$ type 2 houses) sufficiently for them to reside in community 2 rather than community 1 . They are replaced by some residents of community I who used to reside in higher quality houses in that community, thus opening the higher quality houses for some higher income residents who choose the public schools. These effects are usually minor (see the relatively small change in individual house values) compared to others and therefore play virtually no role in the rest of the paper. 
indicated previously, it makes little sense to push $\rho$ much closer to 1 because of the substantial empirical evidence that suggests parents in fact do care about public school spending. Furthermore, even at $\rho=0.7$, public schools have already almost disappeared as peer effects are large enough for enough agents to forego the public sector, consume individualized private education instead and vote public schools out of existence.) Although these results are not surprising, they are illustrative of the potential importance of peer effects as well as the potentially misguided emphasis by state supreme courts on per pupil spending. When $\rho=0$ and local communities use property taxation, communities are stratified along income and wealth lines not because there is any inherent advantage from having high income neighbors but rather because the demand for public education and housing is monotonic in income. Thus, stratification occurs due to differences in final demands for public outputs and houses. As $\rho$ rises, however, there is an inherent advantage high income individuals gain by segregating themselves (assuming, as is done here, that peer quality is perfectly correlated with family income). As a result, Table 3 shows an increasing degree of stratification along income and wealth lines with increasing values of $\rho$ until peer effects become large enough to cause the appearance of private schools. As soon as private schools appear, we observe less residential stratification: 33 once private schools for high income individuals become an option, desirable houses in low income communities become sought after by high income individuals who migrate to take advantage of lower prices without having to endure bad public schools. Again, the appearance of private schools catering to high income residents in community 1 does not improve local public schools directly; but indirectly, the fact that more money is now available per pupil more than offsets, in the eyes of parents, the lower peer quality levels in the public schools. Peer effects thus have the potential of driving the local public goods economy towards substantially larger inequities, but cream skimming private schools can stop and reverse that trend. It is worth emphasizing again that those choosing private schools in poor communities are not the original (pre-private schools) residents of those communities but rather high income migrants who are fleeing communities in which they would be paying a premium for their house due to relatively good public schools. Furthermore, we see the fraction of students in private

33 This is consistent with stylized trends and anecdotal evidence from many US cities in which Catholic Schools open (at subsidized tuitions) and cause an in-migration of middle income families who send their children to those schools. It is also consistent with empirical econometric evidence (Downes and Greenstein (1996)). 
schools leveling off at 0.3333 in community 1 because only one third of the houses in community 1 are sufficiently desirable for high income residents to live there. Thus, once all the residents of those houses are attending private schools, new private schools begin to open in community 2 .

The voucher simulations in the following section begin with the actual equilibrium (with private schools) and find the new equilibrium as different levels of vouchers are introduced. The new equilibria are calculated in much the same way as the initial equilibrium except that the CGE program now begins with the initial equilibrium. Each agent's wealth, however, is now affected by price changes of his equilibrium house, not his initial house endowment (which he sold on his way to the initial equilibrium.) When different magnitudes of a voucher program are simulated, the simulation always begins with the initial equilibrium; i.e. the following tables should not be read as if a program was slowly being phased in.

\section{Private School Vouchers}

Throughout this paper, we will simulate a very simple voucher program, under which each resident of each community is entitled to a voucher of the amount specified by the program. The state government commits to re-imburse private schools for the face value of the voucher, which thus allows residents to use their voucher as part of their tuition. If the face value of the voucher is larger than the tuition of a school, then the school gets paid the tuition and the state keeps the difference. Thus, in equilibrium, tuition is never set below voucher levels. The state pays for the voucher program through an income tax which residents/voters know at the time they make their moving and voting decisions.

\subsection{Private School Vouchers in Locally Financed School Systems}

Table 5 presents equilibrium community averages for all three communities under different levels of state vouchers when all financing for the public school system occurs at the local level. We report here results for both $\rho=0$ and $\rho=0.5$. In the case of $\rho=0$, the results are very straightforward. Since peer effects do not matter and since agents have already chosen school districts in part based on per pupil spending, no one chooses to use vouchers until the level of the voucher comes close to the level of current local public spending in one of the communities. (It is conceivable that some agents could want significantly more spending than is provided in any 
community and thus chooses to make use of vouchers early on. However, agents are already sufficiently segregated, and there are no extremely high income agents whose demand for spending would be sufficiently high in the model. This means that vouchers are not used until they are close to current spending levels.) Once vouchers are sufficiently high for some agents to use them, all agents in that community will use them which implies the local public school collapses from lack of public support, and property taxes fall to zero. ${ }^{34}$ Thus, it is extremely difficult to get a mixture between public and private schools within communities when $\rho=0$. For this reason, while we will continue to report results for $\rho=0$ when they offer insights into different institutional funding mechanisms, we will forego reporting voucher simulations for the uninteresting case of $\rho=0.35$

When $\rho=0.5$, individual responses become more subtle. From the column "PrPeer" in Table 5(b) it is apparent that the first to make use of vouchers are high income (high peer quality) students. Furthermore, private schools arise first in poor communities as private school attendees migrate from high income areas. As "good houses" in community 1 are "used up," private schools appear in community 2 ; and as they are used up there as well, private schools finally appear in the wealthy community. All along, migration of income is from relatively high income areas to relatively low income areas which causes communities to become less stratified in income, property values and wealth levels. This decrease in residential stratification, however, does not benefit public schools in poor communities whose peer quality levels are falling as high peer quality students leave for either private schools or, more often, other communities with better public schools. These are the residents that originally occupied the best houses in the poor communities which they sell to high income immigrants who come for the private school. Thus, public school peer quality levels fall in poor communities with the introduction of vouchers because high peer quality residents are leaving for other communities and are not replaced in the public schools by high peer quality immigrants who choose private schools. At the same time, however, as the pool of local public school students shrinks while public support for local public schools remains above $50 \%$, the median voter public spending outcome produces more funding

34 In some earlier simulations we assumed that public schools would always be available at $\$ 2500$ per pupil, regardless of whether the voting outcome suggests less spending is desired. In those simulations, the transition from the public to the private school system in the presence of peer effects is somewhat smoother.

35 Qualitative results are the same for different reasonable values of $\rho$. In particular, we tried values of $\rho$ ranging from 0.3 to 0.6 . 
per pupil as voucher levels increase. ${ }^{36}$ Thus, per pupil spending on public education in poor communities rises at the same time as peer quality levels fall. Under the specification of $\rho=0.5$ (as well as most other reasonable specifications we tried), however, the former of these effects outweighs the latter to produce a higher perceived level of public school quality in the poor community as vouchers grow. This occurs up to the point when voter support for public schools falls below $50 \%$ at which time the local public school collapses and everyone in community 1 uses the private school vouchers.

The common notion that private school vouchers will cause lower school quality in local public schools therefore does not necessarily hold in a local public finance economy unless we think that spending matters sufficiently little as compared to peer effects. In fact, the perceived public school quality suffers only in community 3 , the wealthiest community, which is losing high income residents to private schools in other communities and thus is losing both peer quality and the constituency for high per pupil spending. Therefore, all three indicators of quality (spending, peer effects and parental perceptions) fall, while at least two of these rise or stay constant in the other communities. This implies that, contrary to common perceptions, it is public schools in wealthy communities that suffer unambiguously from voucher systems while those in poor communities might benefit. Far from increasing inequities in public education, simulations in Table 5 actually demonstrate that vouchers, while not benefitting low income residents directly unless they are of high enough face value, can help equalize local public school quality.

\subsection{Private School Vouchers in State Funded Public School Systems}

We now turn to comparing the results from Table 5 to those in Table 6 in which all public education is assumed to be funded by the state government through a proportional income tax whose rate is set in accordance with majority rule voting by all voters in the state. Furthermore, the state government is assumed to spend equal amounts per pupil on students in all schools regardless of community income. ${ }^{37}$ (This is essentially the California post-Serrano, post-Proposition 13

36 Since those attending private schools bave single peaked preferences for local school spending with peak at zero, an increase in the fraction of local residents who send their children to private schools thus causes the median voter, all else being equal, to shift toward less spending. However, this is more than offset by the fact that the private school attendees live in the best houses and therefore pay a disproportionately large share of local property taxes without taking advantage of local public schools. Thus, per pupil spending in public schools increases.

37 We do not address here the issue of whether average per pupil spending rises or falls as a result of a state takeover of 
system.) Having seen the intuitive results from the $\rho=0$ case in the previous table, we do not repeat this exercise for the rest of the policy environments.

First, we can note that equality of spending certainly does not guarantee equality of outcomes. Unless we think that spending is the only input into education that matters, the substantial stratification of income across communities before the introduction of vouchers yields substantially unequal outcomes when peer effects matter. While this is a simple point, it is often overlooked by policy makers and courts who tend to focus solely on variances in per pupil spending levels as a measure of interjurisdictional inequity in the provision of education.

Second, the pattern of school voucher use is substantially the same as in the previous table. Private schools develop first in the poor community but are catering to high income immigrants while middle to high income residents of the poor community emigrate to other communities. Peer levels in the low income public school therefore fall while per pupil spending levels rise so long as there is above $50 \%$ public support for public education within the community. Again, the two effects are offsetting and parental impressions of public school quality in the community rise modestly (while this time they fall in the middle community). Furthermore, property values rise in the poor community. As the most desirable houses become occupied with private school attendees in the poor community, private schools again begin to develop in the middle income community and then finally, at extremely high voucher levels, in community 3.

While the patterns of private school use and development under the state funded system are therefore similar to those under local funding, the speed of the privatization of education as voucher levels rise is surprisingly slower under state funding than under local funding. One would, perhaps, expect that high income residents will respond to vouchers sooner under state funding because they are farther from their ideal level of spending than they would be under local funding. However, one of the reasons high income residents are so eager to use private schools under local public funding is that, once they migrate to the poor community, they no longer have to pay as high a property tax bill. Under state funding, this advantage of migrating and attending private schools vanishes as high income residents must pay income taxes to support the public system regardless of where they live.

education finance. Since our model does not contain the skewedness of income distributions which is important in such analysis (see Sonstelie and Silva (1995)), it would be ill-suited for this purpose. 
Furthermore, we note that, compared to a locally funded system, a state financed system does not yield nearly as many fiscal benefits for public schools in poor districts. Under a local system, an exit of some community residents into the private system translates into larger per pupil spending in the public school in that community. Under a state system, on the other hand, this same exit leads to an increase in per pupil spending spread across the entire state and not concentrated in one community. This translates into a much smaller improvement in per pupil spending (and no decrease in the interjurisdictional variance) under the state controlled system than under local funding and control. At the same time, however, public schools, at least in the eyes of parents, are still improving despite the outmigration of high income/high peer students from the public school system in poor communities. Finally, in contrast to the previous case, the public school in the wealthy community no longer suffers but rather benefits because now, it too receives additional per pupil funding as individuals shift into private schools.

\subsection{Private School Vouchers Under Local Financing Combined with State Foundation Grants}

Table 7 presents community averages under different levels of per pupil foundation grants funded through a state income tax. (Note that all entries in this table assume the absence of any vouchers program.) Each community is constrained to spend at least the amount of the foundation grant on public schools and is free to add additional per pupil spending funded by local, voterdetermined property taxes. These foundation grants are similar to the "redistributive block grants" analyzed in Nechyba (1996b). Since the grants have only small income effects and no price (or substitution) effects, they are extremely ineffective at raising per pupil spending in any district unless the foundation grant is greater than what the community would have spent to begin with. For example, in Table 7 (a) where $\rho=0$, public spending essentially remains unchanged in community 1 until the foundation grant rises to 0.30 per pupil and thus is binding. The major effect of the grants (which are redistributive in the sense that low income communities receive grants that are larger than the income taxes paid by its residents to fund the grants) is to make low income communities slightly more desirable and high income communities slightly less desirable. This is reflected in the slight convergence of property values, income levels and wealth levels. The interesting difference in Table 7(b) where $\rho=0.50$ lies in the response of private schools to the 
increase in foundation grants. So long as these grants are not binding on any community, private schools continue to exist. In fact, when the foundation grant reaches 0.20 , we see a further migration of high income residents from communities 2 and 3 into community 1 to take advantage of lower property values and private schools. This is due to the fact that the redistributive nature of the grants makes these high income communities somewhat less desirable and thus persuades some of its residents to opt out of the public school system. Once the foundation grant binds in community 1 , however, private schools collapse and their high income/high peer quality clients no longer choose the low income district. They are replaced by lower and middle income residents from the other communities who now find it worthwhile to return to community 1 as the public schools have improved; i.e. they now outbid the potential high income immigrants for the best houses in community 1 .

Table 8 proceeds to simulate the general equilibrium effects of different levels of simple vouchers in the presence of a foundation grant system of 0.40 . While the evolution of private schools with increases in vouchers is the same as before for exactly the same reasons, the effects on public schools from the same type of private school vouchers are now substantially different: By all measures of school quality (pure spending, pure peer effects and parental perceptions), public schools in all communities deteriorate as higher levels of vouchers are introduced. In the poor community, for example, the fact that the foundation grants are given in per pupil amounts, and the fact that the grant is sufficiently large to be binding, implies that local per pupil spending remains the same as relatively high peer quality students are leaving the local public system for other school districts without being replaced by the high income immigrants who are choosing private schools. Thus, the peer quality falls in the community's public school while per pupil spending does not rise as it did under local financing and, to a lesser extent, under state financing. There is, therefore, no opposing effect to the deterioration of public schools brought about by the decline in peer quality, which means parental assessments of the local public schools fall (which in turn pushes further high peer quality students into private schools and out of the community). While vouchers still have the effect of decreasing the stratification of income, wealth and property values across communities, they can no longer improve education for both public and private students under a binding foundation grant system. 38 
4.4. Private School Vouchers under A System of Local Financing and District Power Equalization

Finally, we examine the effect of private school vouchers under district power equalization (DPE). DPE is a state program that sets a guaranteed per pupil tax base $P_{i}$ for each community $i$ and guarantees the community a per pupil spending of $\mathrm{t}_{\mathrm{i}} \mathrm{P}_{\mathrm{i}}$. If the actual per pupil tax base is below the guaranteed base, the state government makes up the difference; if the actual level is above the guaranteed base, the state government collects the balance and uses it to fund the payments to low base communities. As demonstrated in Nechyba (1996b), this system is equivalent to a system of positive and negative matching grants that contains both income and price (substitution) effects. We will assume here that the state program is revenue neutral; that is, the bases are set in such a way as to insure that the sum of the negative payments to high income communities is equal to the sum of positive payments to low income communities. Furthermore, we will say that a program is " $x \%$ base equalizing" if it sets bases such that the high income community's base is $x \%$ higher than the middle income community's base which in turn is $\mathrm{x} \%$ higher than the poor community's. When $\mathbf{x}=0$, we will call the program "Full Revenue Neutral District Power Equalization."

Table 9 summarizes the general equilibrium effects of different degrees of revenue neutral DPE assuming both $\rho=0$ and $\rho=0.5$. (These results are in the absence of any voucher programs.) For the same reasons as in the last section, increasing equalization leads to decreases in stratification in income, wealth and property values. (Due to the additional price effects of the implicit matching grants, these effects are somewhat larger.) Also for similar reasons, private schools collapse with increasing degrees of district power equalization as public schools improve in poor districts causing middle income residents to return to the better houses in community 1 . Unlike the foundation grants, DPE is, however, effective at reducing public school spending disparities between school districts even at low levels of the program. This is a direct result of the fact that, unlike foundation grants, DPE lowers the price of public schools substantially in poor communities and raises it substantially in high income communities. As can be seen from Table 9(a), it is easily possible for a full DPE program to even reverse the order of communities in terms of their per pupil spending levels. ${ }^{39}$

38 This is, in spirit, similar to the Epple and Romano (1996) and Manski (1992) result in that the level of public school spending in the poor community is exogenous to the local political process. Therefore, the positive fiscal benefits from having high income residents who do not use local public schools do not arise. 
Next we demonstrate the general equilibrium effects of private school vouchers in the presence of district power equalization in Table 10. The striking feature in this table is the very different pattern of private school development compared to all three previous institutional settings. In particular, while under local financing, state financing, and foundation grants it was always the case that private schools appeared slowly and in poorer communities first, we see here a rapid switch to private schools in the wealthiest community. While high income residents do migrate into the poor community and a modest amount of private school activity takes place there as the level of vouchers increases, the bulk of private school attendance occurs in community 3 for most levels of the voucher program. Once the most desirable houses in community 1 are filled with high income private school attendees, the remaining homes are held by residents who value the DPE-improved local public school. Similarly, only a limited number of houses are available to high income private school attendees in community 2 which still leaves a large number of high income agents in community 3 who are dissatisfied with the DPE-induced reduction in educational quality in their public schools. Furthermore, unlike in the case of state funding or foundation grants, residents of high income communities can eliminate the adverse price effects from DPE by switching to private schools. (This is because redistribution to low income communities occurs only to the extent that the high income community has positive tax rates. If everyone in community 3 switches to private schools, local tax rates can fall to zero and thus stop redistribution.) Thus, a sufficient number of community 3 residents choose to abandon the public school system to remove public support from the system and drive property tax rates in community 3 to zero. We thus see the collapse of the public school system first in the wealthiest community under DPE because that community is under extreme adverse pressures from the DPE program, pressures that can be eliminated (unlike foundation grants) by abandoning the public school system.

While per pupil spending rises in community 1 as a result of the exit from the public system, this increase is not nearly as big as it would have been had the public schools in community 3 survived. The collapse of those schools severely undermines district power equalization which relies on revenues from the high income districts to finance price subsidies to low income districts.

39 For a more complete treatment of the relative differences between district power equalization and foundation grants on both local and state government behavior within the context of this model, see Nechyba (1996b). 
As a result, while per pupil spending does rise and help offset the decline in peer quality in the low income public schools (from the exit to the private system), it is now no longer sufficient to cause an improvement in parental perceptions of educational quality in that community. Thus, unlike the case of pure local funding as well as state funding, parental perceptions of public school quality falls in all three communities. This decrease is not, however, as large as the decrease observed under foundation grants. The latter is true because, while per pupil spending remains constant as high peer quality students leave for other schools under binding foundation grants, per pupil spending can (and does) nevertheless rise under DPE. Thus, even if the effect is not large enough, there is a positive effect on local public spending (that does not have a parallel under foundation grants) as vouchers are introduced under.

\section{Summary, Limitations, Empirical Questions and Conclusion}

This paper has extended the literature on computational models of private school choice by endogenizing local public outcomes and local populations, and by considering how competition affects local public schools under a variety of institutional settings. While we have reported simulation results mainly for the case in which parents perceive peer effects to be as important as per pupil spending, the results also hold for other reasonable levels of perceived peer quality effects. We can thus come to some broad generalizations and point to open empirical questions:

1. In the absence of private schools, the presence of peer effects causes substantial increases in interjurisdictional stratification and inequities in the provision of public schools. While even under zero peer effects we expect disparities to arise due to different demands for public spending by different income groups in different communities, the presence of peer effects that are correlated with socioeconomic status provides additional incentives for high income types to separate into their own communities. As perceived peer effects become unrealistically high, individuals abandon the public schools to attend more tailor-made private schools. Although we have argued strongly that the available evidence points to the presence of such perceived peer effects, to what extent peer effects play a large role in improving actual school quality remains an unsettled empirical question. The normative interpretation of our positive results clearly depends critically on a more objective definition and understanding of school quality. 
2. Throughout the analysis, whenever private schools arise either because of high peer quality effects or because of private school vouchers, stratification of income, wealth and property values across communities becomes weaker. More precisely, high income/high peer quality types migrate to low income communities with the intention of paying lower house prices and taxes and sending their children to private school. Thus, private schools appear first in poor communities, but they cater not to the original residents but rather to high income immigrants.

3. Although the emergence of private schools thus causes greater interjurisdictional mixing between income types, public schools in poor communities lose high peer quality students. This occurs because those leaving to make room for the high income, private-schoolconsuming immigrants are the former residents of the best houses in the poor community who are also the highest income residents. These parents and students leave the local public system in the poor community not with the intention of attending private schools but rather to attend public schools elsewhere. They leave because the higher income immigrants who wish to attend private schools are willing to pay more for the houses the emigrants originally occupied.

4. The previous two points can be summarized as follows: The presence of private schools (and the introduction of vouchers) increases school-based stratification while it decreases residence-based stratification. This decrease in residence-based stratification (which is consistent with some evidence cited in the text) creates fiscal benefits for public school students in poor areas when public schools are funded, at least in part, locally. More precisely, those moving into the community do not use local public schools but still pay a disproportionately large share of local taxes. Therefore, even though they may vote for less spending, per pupil spending rises (unless more than $50 \%$ of voters send their children to private schools.)

5. To the extent that peer quality matters not only in schools but also in communities in general (as suggested by Durlauf (1996), Wilson (1987), Jencks and Mayer (1990), Crane (1991) and others), the decrease in residential stratification is a positive effect of vouchers that has not previously been emphasized. We do not, however, explore these neighborhood effects in the current paper. If neighborhood extemalities are primarily positive and run from higher income agents to lower income agents, the descriptive results of the analysis do not change 
substantially. (High income individuals still move to good houses in low and middle income neighborhoods when sending their children to private schools.) At the same time, the interpretation of the results would change because the decrease in residential stratification would then not only be potentially equity-enhancing (because of fiscal benefits to those attending public schools in low income communities) but also efficiency enhancing in that greater residential mixing of agents is Pareto improving. However, if negative neighborhood externalities also run from low income agents to high income agents, the migration effects might be muted, and no clear efficiency interpretation could be given. Unfortunately, while there is widespread speculation that non-school related neighborhood effects are important, there is little agreement exactly what form these extemalities take. Furthermore, there is little empirical evidence regarding the extent to which perceived neighborhood peer effects (which motivate migration choices) differ from actual neighborhood effects.

6. The extent to which the loss in public school peer quality in low income communities (resulting from an increase in vouchers) affects public school quality depends on the degree to which parental perceptions of the relative importance of peer quality are correct as well as the institutional setting used to finance public education. Under both local funding and state funding, per pupil spending rises in the poor community and more than offsets the loss in peer quality if parental perceptions are accurate (or if they overestimate the importance of peer effects). Under foundation grants and district power equalization, on the other hand, local public schools worsen in the poor community because per pupil spending either remains constant or does not rise sufficiently much to offset the losses in peer quality (unless parents are overestimating the importance of peer effects.) Our simulations suggest that if we are primarily concerned about parental perceptions about public school quality in poor communities (or, for that matter, about per pupil spending in poor public schools), vouchers are most desirable under a locally funded school system and become progressively less desirable under state funding, district power equalization and foundation aid. Again, better empirical evidence on which of our "quality" measures (parental perceptions, spending, or peer quality) accurately reflect actual school quality is needed for a full normative analysis of our positive results. 
7. Finally, the results also have implications regarding the targeting of vouchers. It is often argued that the equity implications of private voucher proposals become significantly more favorable when the vouchers are targeted at low income residents or at low income communities. However, the distinction between these two ways of targeting is quite important. If the vouchers are targeted at low income parents, our simulation results indicate that they will have to be of fairly high face value in order to convince low income parents to opt out of the public system. If however, they are targeted to low income communities (as recently done in California), then our results remain intact as long as immigrants into those communities can make use of vouchers as well. Again, high income residents will migrate to take advantage of the vouchers which is something they are already doing in the model even when vouchers are not targeted. Thus, our analysis suggests that targeting either makes the program less effective or is no different than an untargeted program depending on how the targeting is accomplished.

We would like to conclude by emphasizing that, while we think these results are new in the literature and quite relevant for thinking more deeply about vouchers, several limitations should be kept in mind. First, many of our interpretations may have to be modified as new empirical evidence regarding the issues raised in the points above emerges. Second, we have assumed that all agents in this model are perfectly informed. Often, a criticism of vouchers has been that low income parents may not be informed enough to make use of vouchers, and thus previous models overpredict the effectiveness of vouchers in getting low income parents to exert competitive pressures on their public schools. While we think that this is a valid criticism, it is not as relevant for our results as it was in the previous literature. In particular, low income agents are not the ones choosing to use the vouchers, at least not at relatively low voucher levels. Rather, high income residents that migrate into low income communities are using the vouchers and, we think, can be expected to be more informed. Those residents in poor districts that are leaving the the low income public schools are not doing so because they are choosing to use vouchers but rather because market pressures drive them to move to a different community and a different public school.

Third, one of the major political hurdles to implementing vouchers is that currently a large number of children already attend private schools. A broad voucher program will thus be costly 
even if it does not achieve any change in behavior. In our model, however, few children attend private schools without a voucher program. We commented before that we think this is due to the fact that we have assumed identical preferences for all agents while, in the real world, some agents have preferences for particular forms of private education quite apart from anything having to do with spending levels or straight peer effects. Our model does not capture those types of private school consumers. Also we have not explicitly considered agents with very high incomes who would choose private schools even under the current assumption if identical preferences.

Fourth, in the absence of construction and renovation, migration only occurs to the extent to which acceptable housing can be found in low income communities. ${ }^{40}$ We think that most communities are in fact not perfectly homogeneous in housing quality and that at least some relatively more attractive housing opportunities exist even in most low income jurisdictions. Furthermore, although more empirical studies are needed, available anecdotal evidence regarding subsidized Catholic schools suggests that middle income agents often do, in fact, migrate to low income communities to take advantage of private schools there. Keeping in mind that all agents in our model are "middle income" (given a top household income of $\$ 80,000$ ), this is consistent with our results. The inclusion of very high income agents, however, would result in those agents choosing private schools without migrating from the best houses located in the best communities.

Finally, we should emphasize once again that we have made a series of assumptions that we thought, a priori, very much "stacked the deck" against vouchers. By assuming away all beneficial effects from increased competition because all schools, public and private, are efficient even without vouchers, we have eliminated the main economic argument in favor of vouchers. Furthermore, we assumed private schools are extreme "cream skimmers" that discriminate against low income/low peer quality students. Thus, we have not only eliminated the common efficiency argument for vouchers but also assumed a private sector that seems less than equity oriented. Still, we demonstrate that the equity argument against vouchers holds only under certain institutional settings or when school peer effects are larger than recognized by parents. Furthermore, since vouchers are demonstrated to reduce residential stratification, they may bring about positive neighborhood effects in low income communities that have not been part of the previous analysis.

40 The model could also be extended to include construction and renovation which would strengthen our migration results as well as give rise to them even if housing was uniformly bad in low income communities to begin with. 


\section{References}

Arnott, R. and J. Rowse (1987): "Peer Group Effects and Educational Attainment," Journal of Public Economics 32,287 305 .

Becker, Gary S. (1991): A Treatise on the Family, Cambridge: Harvard University Press.

Benabou, R. (1992): "Workings of a City: Location, Education, and Production," Quarterly Journal of Economics, 619-51

Brueckner, J. and K. Lee (1989): "Club Theory with Peer-Group Effect," Regional Science and Urban Economics 19, 399420 .

Coleman, James S. (1966): Equality of Educational Opportunity, Washington, D.C.: U.S.GPO.

De Bartolome, C. (1990): "Equilibrium and Inefficiency in a Community Model with Peer Group Effects," JPE 98, 110-33.

Dewey, James; Thomas A. Husted and Lawrence W. Kenny (1995): “Are Educational Inputs Irrelevant?: A Reexamination of the Evidence," mimio.

Downes, Thomas A. and Shane M. Greenstein (1996): "Understanding the Supply Decisions of Non-Profits: Modelling the Location of Private Schools," The Rand Journal, forthcoming.

Dunz, K. (1985): "Existence of Equilibrium with Local Public Goods and Houses," SUNY-Albany Department of Economics Discussion Paper \#201

Durlauf, S. (1996): “A Theory of Persistent Income Inequality," Journal of Economics Growth 1, 75-94.

Epple, D. and R. Romano (1996): "Competition between Private and Public Schools, Vouchers and Peer Effects," American Economic Review, forthcoming.

Epple, D., R. Filimon and T. Romer. (1993): "Existence of Voting and Housing Equilibrium in a System of Communities with Property Taxes," Regional Science and Urban Economics 23, 585-610.

Evans W., W. Oates and R. Schwab (1992): "Measuring Peer Group Effects: A Study of Teenage Behavior," Journal of Political Economy 100, 968-91.

Fernandez, Raquel and Richard Rogerson (1995): "Education Finance Reform and Investment in Human Capital: Lessons from California," NBER working paper \#5369.

Friedman, M. (1955): "The Role of Government in Education," in Economics and the Public Interest (R. Solo, Ed.). New Brunswick: Rutgers University Press.

Friedman, M. (1962): Capitalism and Freedom, Chicago: University of Chicago Press.

Glomm, Gerbard and B. Ravikumar (1995): "Vouchers, Public and Private Education, and Income Distribution," Econometrics and Economic Theory Working Paper No. 9508, Michigan State University.

Grosskopf, S., K. Hayes, L. Taylor and W. Weber (1995): "On Competition and School Efficiency," mimio.

Hamilton, Bruce (1975): "Zoning and Property Taxes in a System of Local Governments," Urban Studies 12, $205-11$.

Hanushek, E. (1986): "The Economics of Schooling: Production and Efficiency in Public Schools," Journal of Economic Literature 24, 1147-117.

Henderson, V., P. Mieszkowski and Y. Sauvageau (1978): "Peer Group Effects and Educational Production Functions," Journal of Public Economics 10, 97-106.

Houtenville, Andrew J. (1996): "Parental Effort, Student Achievement, and the Quality of Schooling," mimio, University of New Hampshire.

Hoxby, C. M. (1994): "Do Private Schools Provide Competition for Public Schools?", NBER working paper \# 4978.

Hoyt, William H. and Kangoh Lee (1996): "Educational Vouchers, Welfare Effects, and Voting," mimio.

Link, C. and J. Mulligan (1991): “Classmates' Effects on Black Student Achievement in Public School Classrooms,” Economics of Education Review 10, 297-310.

Long, James E. and Eugenia F. Toma (1988): "The Determinants of Private School Attendance, 1970-1980," Review of Economics and Statistics, 351-57.

Manski, C. (1993): "Identification of Endogenous Social Effects: the Reflection Problem," Review of Economic Studies $60,531-42$.

Manski, C. (1992): "Educational Choice (Vouchers) and Social Mobility," Economics of Education Review 11, $351-69$.

Moe, T. (ed) (1995): Private Vouchers, Hoover Institution Press, Stanford, CA

Moe, T. and K. Shotts (1996): "Computer Models of Educational Institutions: The Case of Vouchers and Social Equity," Journal of Education Policy, forthcoming. 
Nechyba, T. (1996a): "Existence of Equilibrium and Stratification in Local and Hierarchical Tiebout Economies with Property Taxes and Voting," NBER Technical Working Paper \#190.

Nechyba, T. (1996b): “A Computable General Equilibrium Model of Intergovernmental Aid," Joumal of Public Economics. forthcoming. (Also NBER working paper \#5420)

Nechyba, T. (1996c): "Fiscal Federalism and Local Public Finance: A Computable General Equilibrium (CGE) Framework." International Tax and Public Finance, forthcoming.

Rose-Ackerman, S. (1979): "Market Models of Local Government: Exit, Voting, and the Land Market," Journal of Urban Economics 6, 319-37.

Rubinfeld, D. (1995): "Califomia Fiscal Federalism: A School Finance Perspective," mimio.

Schwab, R. and W. Oates (1991): "Community Composition and the Provision of Local Public Goods," Joumal of Public Economics 44, 217-37.

Schmidt, Amy B. (1992): "Private School Enrollments in Metropolitan Areas," Public Finance Quarterly 20, $298-320$.

Scotchmer, S. (1994): "Public Goods and the Invisible Hand," in Modern Public Finance, (J. Quigley and E. Smolensky. eds.), Cambridge: Harvard University Press.

Sonstelie, Jon and Fabio Silva (1995): "Did Serrano Cause a Decline in School Spending?" National Tax Journal 48, 199 215.

Stiglitz, J. (1974): “The Demand for Education in Public and Private School Systems," Journal of Public Economics 3 , 349-85.

Summers, A. and B. Wolfe (1977): "Do Schools Make a Difference?", American Economic Review, 639-52.

Tiebout, C. (1956): “A Pure Theory of Local Expenditures," Joumal of Political Economy 64, 416-24.

Toma, Eugenia Froedge (1996): "Public Funding and Private Schooling Across Countries," Journal of Law and Economics, forthcoming.

Vandenberghe, V. (1996): Functioning and Regulation of Educational Quasi-Markets, unpublished Pb.D. dissertation, Institut de Recberches Economiques et Sociales (IRES), Louvain-la-Neuve, Belgium.

Westhoff, F. (1977): "Existence of Equilibria in Economies with a Local Public Good," Journal of Economic Theory, 14, 84-112. 
Simulation Literature on Private School Vouchers and Peer Effects

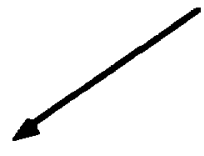

Epple and Romano (1996)

Public Schools

Private Schools

Institutions funding Public Schools

Public Schoo Choice
Profit-maximizing, (based on peer quality)

Per Pupil Spending

Exogenously Determined price discriminating
Per Pupil Spending Exogenously Determined

\section{Maximize number of students, \\ no price discrimination}

(i) Efficient
(ii) Rent Seeking

is Endogenous (voting)

4 Institutional Settings Considered:

(i) local voting under property tax

(ii) state voting under income tax

(iii) state foundation aid with local marginal funding

(iv) district power equalization

3 Communities with different quality public schools.

(Open Enrollment implies (Different Communities all public schools are identical)

but no mobility between communities) mobility across communities. no open enrollment 
FIGURE 2

\section{CGE Program to Calculate the Public School Benchmark Equilibrium}

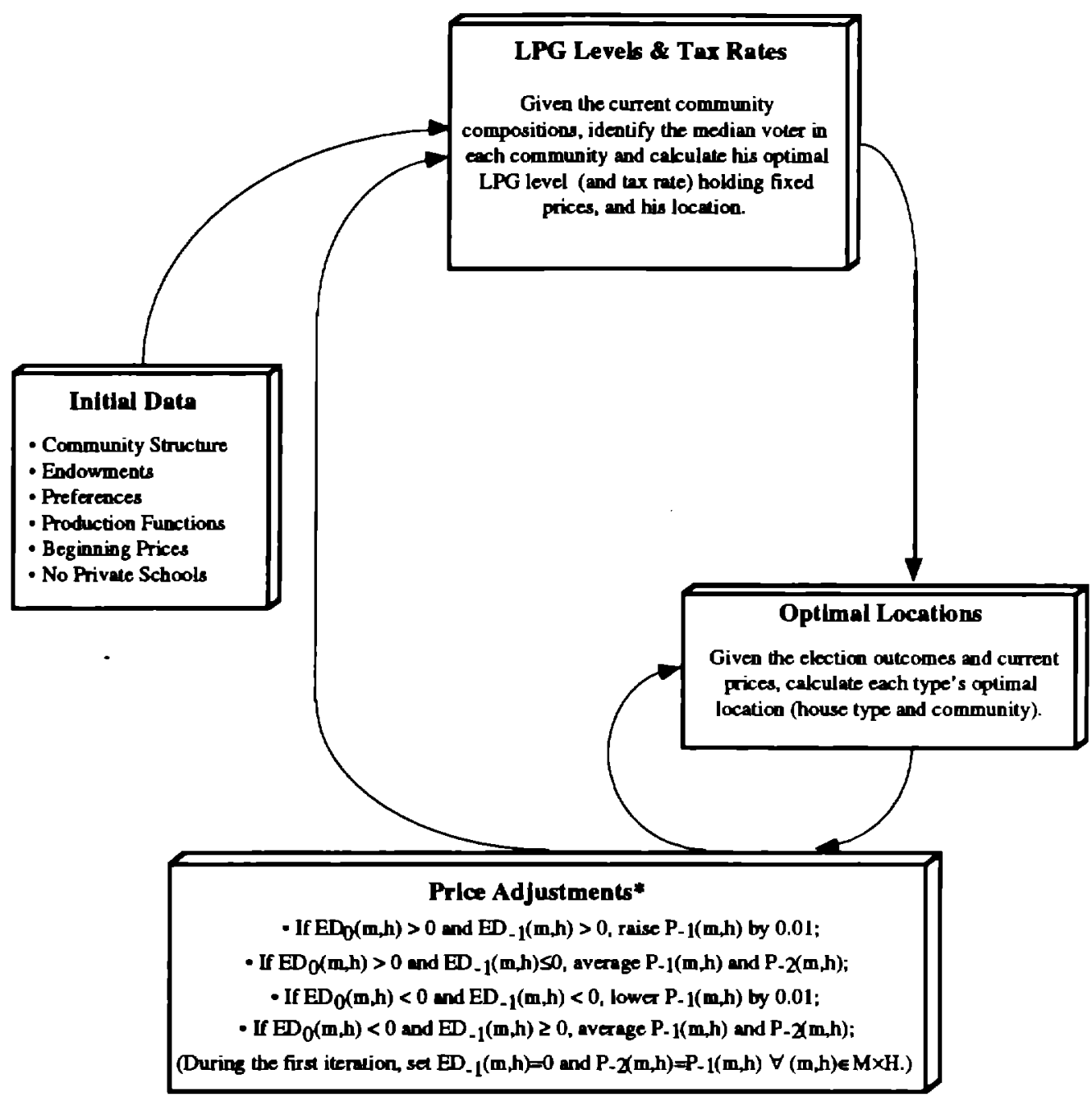

* $\mathrm{ED}_{0}(\mathrm{~m}, \mathrm{~h})$ and $\mathrm{ED}_{-1}(\mathrm{~m}, \mathrm{~h})$ stand for excess demand for $(\mathrm{m}, \mathrm{h})$ during the current and previous iterations respectively.

$P_{-1}(m, h)$ and $P_{-2}(m, h)$ stand for the prices of $(m, h)$ one and $t$ wo iterations prior to the current iteration. 


\section{FIGURE 3}

CGE Program to Calculate the Actual Equilibrium with Private Schools from the Benchmark Public School Equilibrium

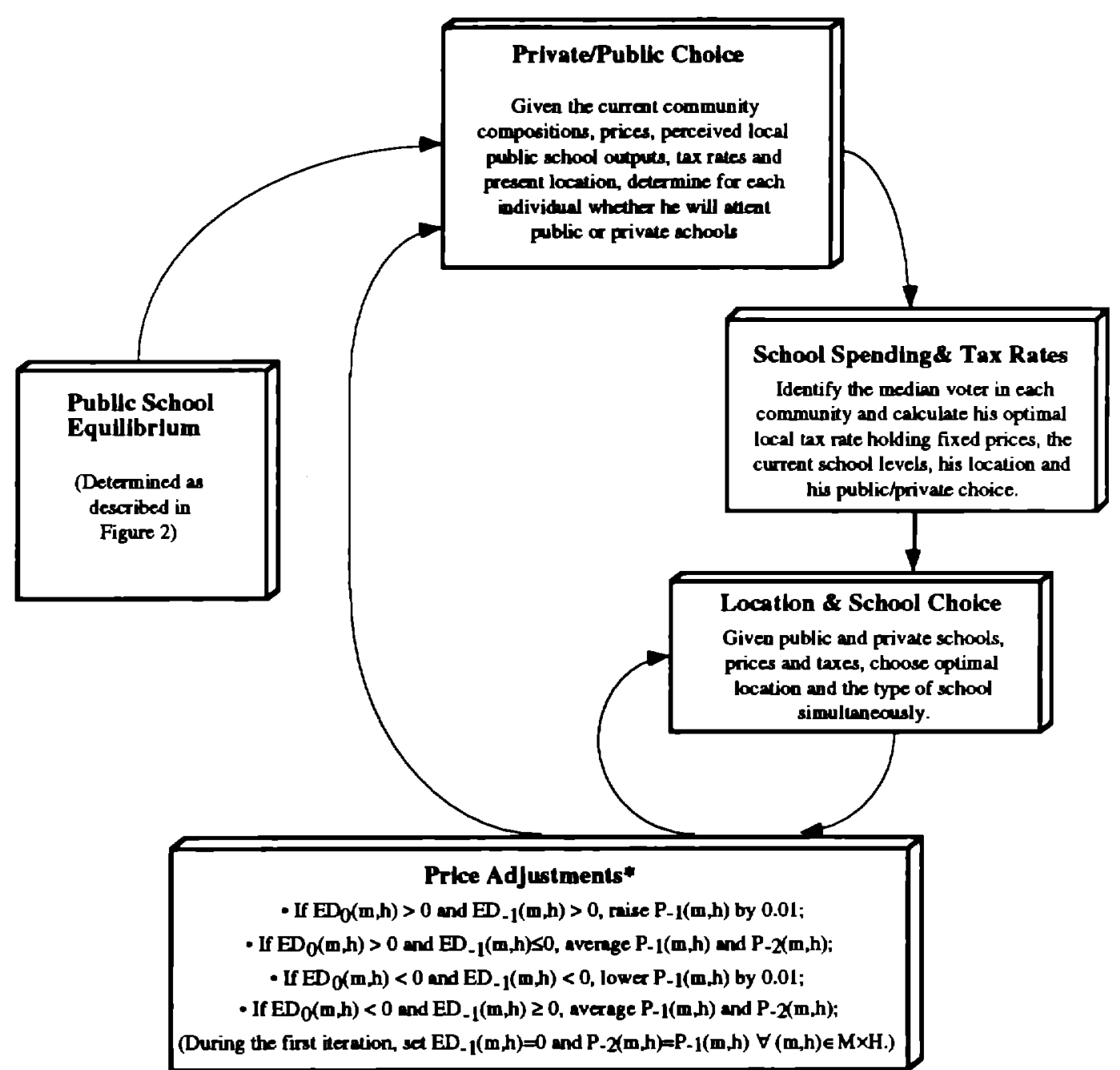

- $\operatorname{ED}_{0}(m, h)$ and $E_{-1}(m, h)$ stand for excess demand for $(m, h)$ during the current and previous iterations respectively. $P_{-1}(m, h)$ and $P_{-2}(m, h)$ stand $f a r$ the prices of $(m, h)$ one and two iterations priar to the current iteration. 
TABLE 1

\section{Summary of Computable General Equilibrium Model Including Parameter Values}

General Model

CGE Version and Parameters

\begin{tabular}{|c|c|c|}
\hline Community Structure & $\mathrm{C}=\left\{\mathrm{C}_{\mathrm{mh}} \subset \mathrm{N} I(\mathrm{~m}, \mathrm{~h}) \in \mathrm{M} \times \mathrm{H}\right\}$ & $\mathrm{N}=[0,1] ; \mathrm{M}=\{1,2,3\} ; \mathrm{H}=\{1,2,3\} ;$ and $\mu\left(\mathrm{C}_{\mathrm{in}}\right)=\frac{1}{9} \forall(\mathrm{m}, \mathrm{h})$ \\
\hline Endowment Types & $\mathrm{E}=\left\{\mathrm{E}_{\mathrm{mhi}} \mid(\mathrm{m}, \mathrm{h}, \mathrm{i}) \in \mathrm{M} \times \mathrm{H} \times \mathrm{I}\right\}$ & $\begin{array}{l}\mathrm{I}=\{1,2,3,4,5\} ; \mu\left(\mathrm{E}_{\mathrm{mhi}}\right)=\frac{1}{45} \forall(\mathrm{m}, \mathrm{h}, \mathrm{i}) ; \text { and } \\
\left(z\left(\mathrm{e}_{\mathrm{mh} 1}\right), \ldots, z\left(\mathrm{e}_{\mathrm{mhS}}\right)\right)=(2,3.5,5,6.5,8) \forall(\mathrm{m}, \mathrm{h})\end{array}$ \\
\hline Preferences $^{\mathbf{a}}$ & $\mathrm{U}=\left(u^{\mathrm{n}}: \mathrm{M} \times \mathrm{H} \times R_{+}^{\overline{\mathrm{m}}+2} \rightarrow R_{+} \mid \mathrm{n} \in \mathrm{N}\right\}$ & $\begin{array}{l}u^{\mathrm{n}}(\mathrm{m}, \mathrm{h}, \mathrm{s}, \mathrm{c})=\mathrm{k}_{\mathrm{mb}} \mathrm{s}^{\beta} \mathrm{c}^{\gamma} \forall \mathrm{n} \in \mathrm{N} \text { where } \\
\quad(\beta, \gamma)=(0.06,0.64),{ }^{\mathrm{a}} \text { and } \\
\quad\left(\mathrm{k}_{11}, \ldots, \mathrm{k}_{13}, \mathrm{k}_{21}, \ldots, \mathrm{k}_{33}\right)= \\
(0.82,0.89,0.96,0.85,0.95,1.05,0.93,1.03,1.13)\end{array}$ \\
\hline
\end{tabular}

Perceived Production

of School Quality

$f_{\mathrm{s}}: R_{+}^{2} \rightarrow R_{+}$

$\mathrm{s}=f_{\mathrm{s}}\left(\mathrm{Z}_{\mathrm{s}}, \mathrm{I}_{\mathrm{s}}\right)=\mathrm{Z}_{\mathrm{s}}^{(1-\rho)} \mathrm{P}_{\mathrm{s}}^{\rho}$

a The actual specification of the utility function in the CGE programs contains an additional arguments (a state public good) with Cobb Douglas coefficient $\alpha=0.13$. While in past papers (Nechyba (1996b,c)) the level of state public good spending has been determined endogenously, it is exogenous in this model (set consistent with New Jersey data) and financed through an exogenously set state income tax. Thus, it becomes a constant and irrelevant for the choices analyzed in the current paper. 
TABLE 3

Equilibrium Without Fiscal Interaction and $\rho=0.50$

(a) Public School Benchmark Equilibrium

(i.e. No Private Schools)

Community Averages*

\begin{tabular}{lcccccccc}
\hline & Income & Wealth & Property & Prop. Tax & School & LPSpend & LPeer & $\%$ Private \\
\hline Community 1 & 3.0000 & 3.8773 & 0.4983 & 0.5671 & 0.2377 & 0.2826 & 0.2000 & 0.0000 \\
Community 2 & 5.0000 & 6.1405 & 1.0325 & 0.4017 & 0.3718 & 0.4147 & 0.3333 & 0.0000 \\
Community 3 & 7.0000 & 8.2925 & 1.7800 & 0.2863 & 0.4877 & 0.5097 & 0.4667 & 0.0000 \\
\hline
\end{tabular}

House Values

\begin{tabular}{lcccc}
\hline & Type 1 & Type 2 & Type 3 & Average Private Peer Level \\
Community 1 & 0.2750 & 0.4750 & 0.7450 & 0.0000 \\
Community 2 & 0.5475 & 1.0050 & 1.5450 & Average Private Output \\
Community 3 & 1.1700 & 1.7700 & 2.4000 & 0.0000 \\
\hline
\end{tabular}

(b) Actual Equilibrium (with Private Schools)

Community Averages*

\begin{tabular}{lcccccccc}
\hline & Income & Wealth & Property & Prop. Tax & School & LPSpend & LPeer & \%Private \\
\hline Community 1 & 3.4000 & 4.3009 & 0.5325 & 0.5325 & 0.2523 & 0.3109 & 0.2048 & 0.0667 \\
Community 2 & 4.6000 & 5.7523 & 1.0075 & 0.3976 & 0.3505 & 0.4006 & 0.3067 & 0.0000 \\
Community 3 & 7.0000 & $\mathbf{8 . 2 6 8 4}$ & 1.7683 & 0.2861 & 0.4859 & 0.5060 & 0.4667 & 0.0000 \\
\hline
\end{tabular}

House Values

\begin{tabular}{lcccc}
\hline & Type 1 & Type 2 & Type 3 & Average Private Peer Level \\
Community 1 & 0.3200 & 0.5350 & 0.7900 & 0.4439 \\
Community 2 & 0.5425 & 0.9800 & 1.5000 & Average Private Output \\
Community 3 & 1.1600 & 1.7650 & 2.3800 & 0.5333 \\
\hline
\end{tabular}

*Note: All dollar values are scaled by $\$ 10000$. Property values are expressed as annual payments on a fixed rate mortgage at $7 \%$ interest. Property tax rates may appear high because they are tax rates on these annual payments, not on the full value of the property. 
TABLE 4

Benchmark Equilibria with Local Financing and Different Levels of Peer Effects $(\rho)^{*}$

\begin{tabular}{|c|c|c|c|c|c|c|c|c|c|}
\hline$\rho$ & Income & Wealth & Property & Prop. Tax & School & LPSpend & LPeer & PrPeer & \%Private \\
\hline \multicolumn{10}{|c|}{ Community 1} \\
\hline 0.00 & 3.3000 & 4.3900 & 0.6550 & 0.4247 & 0.2782 & 0.2782 & 0.2200 & $* * * *$ & 0.0000 \\
\hline 0.20 & 3.1000 & 4. 1453 & 0.6383 & 0.4287 & 0.2587 & 0.2736 & 0.2067 & $* * * *$ & 0.0000 \\
\hline 0.40 & 3.0000 & 3.8755 & 0.5550 & 0.4576 & 0.2308 & 0.2540 & 0.2000 & $* * * *$ & 0.0000 \\
\hline 0.50 & 3.4000 & 4.3009 & 0.5450 & 0.5325 & 0.2523 & 0.3109 & 0.2048 & 0.5333 & 0.0667 \\
\hline 0.60 & 3.9000 & 4.7877 & 0.5950 & 0.5369 & 0.2585 & 0.4577 & 0.1633 & 0.4534 & 0.3333 \\
\hline 0.70 & 3.5000 & 4.5310 & 0.5033 & 0.0000 & $* * * *$ & $* * * *$ & $* * * *$ & 0.2333 & 1.0000 \\
\hline \multicolumn{10}{|c|}{ Community 2} \\
\hline 0.00 & 5.2000 & 6.3027 & 1.0250 & 0.3880 & 0.3977 & 0.3977 & 0.3467 & $* * * *$ & 0.0000 \\
\hline 0.20 & 5.4000 & 6.4143 & 1.0317 & 0.3977 & 0.3997 & 0.4103 & 0,3600 & $* * * *$ & 0.0000 \\
\hline 0.40 & 5.7000 & 6.6390 & 1.0592 & 0.4332 & 0.4255 & 0.4589 & 0.3800 & $* * * *$ & 0.0000 \\
\hline 0.50 & 4.6000 & 5.7523 & 1.0075 & 0.3976 & 0.3502 & 0.4006 & 0.3067 & $* * * *$ & 0.0000 \\
\hline 0.60 & 5.0000 & 5.8930 & 1.0883 & 0.3476 & 0.3191 & 0.4178 & 0.2606 & 0.5333 & 0.2667 \\
\hline 0.70 & 5.0000 & 6.0140 & 1.0367 & 0.0000 & $* * * *$ & $* * * *$ & $* * * *$ & 0.3333 & 1.0000 \\
\hline \multicolumn{10}{|c|}{ Community 3} \\
\hline 0.00 & 6.5000 & 7.5573 & 1.5700 & 0.2706 & 0.4248 & 0.4248 & 0.4333 & $* * * *$ & 0.0000 \\
\hline 0.20 & 6.5000 & 7.7037 & 1.5933 & 0.2686 & 0.4290 & 0.4279 & 0.4333 & $* * * *$ & 0.0000 \\
\hline 0.40 & 6.3000 & 7.7563 & 1.6567 & 0.2678 & 0.4340 & 0.4436 & 0.4200 & $* * * *$ & 0.0000 \\
\hline 0.50 & 7.0000 & 8.2684 & 1.7683 & 0.2861 & 0.4859 & 0.5060 & 0.4667 & $* * * *$ & 0.0000 \\
\hline 0.60 & 6.1000 & 7.8553 & 1.8567 & 0.2714 & 0.4521 & 0.4930 & 0.4067 & $* * * *$ & 0.0000 \\
\hline 0.70 & 6.5000 & 8.0450 & 1.9800 & 0.2634 & 0.4698 & 0.6518 & 0.4083 & 0.5333 & 0.2000 \\
\hline
\end{tabular}

${ }^{*}$ As peer effects rise, the utility functions are re-parameterized to keep spending roughly constant; i.e. $\beta^{*} \rho=0.06$ in all simulations. 
TABLE 5

Equilibria with Different Levels of Vouchers and Local Financing

\begin{tabular}{|c|c|c|c|c|c|c|c|c|c|}
\hline Voucher & Income & Wealth & Property & Prop. Tax & School & LPSpend & LPeer & PrPeer & $\%$ Private \\
\hline \multicolumn{10}{|c|}{ (a) Peer Effect: $\rho=0.0$} \\
\hline \multicolumn{10}{|c|}{ Community 1} \\
\hline $0.00-0.25$ & 3.3000 & 4.3900 & 0.6550 & 0.4247 & 0.2782 & 0.2782 & 0.2200 & $* * * *$ & 0.0000 \\
\hline 0.30 & 3.7000 & 4.6755 & 0.7800 & 0.0000 & $* * * *$ & 0.0000 & $* * * *$ & 0.2467 & 1.0000 \\
\hline 0.35 & 3.6000 & 4.6793 & 0.80330 & 0.0000 & $* * * *$ & 0.0000 & $* * * *$ & 0.2400 & 1.0000 \\
\hline 0.40 & 3.7000 & 4.5607 & 0.6042 & 0.0000 & $* * * *$ & 0.0000 & $* * * *$ & 0.2467 & 1.0000 \\
\hline \multicolumn{10}{|c|}{ Community 2} \\
\hline $0.00-0.25$ & 5.2000 & 6.3027 & 1.0250 & 0.3880 & 0.3977 & 0.3977 & 0.3467 & $* * * *$ & 0.0000 \\
\hline 0.30 & 5.2000 & 6.0358 & 0.8367 & 0.4827 & 0.4039 & 0.4039 & 0.3467 & $* * * *$ & 0.0000 \\
\hline 0.35 & 4.9000 & 5.9603 & 0.8183 & 0.4969 & 0.4066 & 0.4066 & 0.3267 & $* * * *$ & 0.0000 \\
\hline 0.40 & 4.9000 & 6.0335 & 0.9617 & 0.0000 & $* * * *$ & 0.0000 & $* * * *$ & 0.3267 & 1.0000 \\
\hline \multicolumn{10}{|c|}{ Community 3} \\
\hline $0.00-0.25$ & 6.5000 & 7.5573 & 1.5700 & 0.2706 & 0.4248 & 0.4248 & 0.4333 & $* * * *$ & 0.0000 \\
\hline 0.30 & 6.1000 & 7.2670 & 1.3617 & 0.3031 & 0.4127 & 0.4127 & 0.4067 & $* * * *$ & 0.0000 \\
\hline 0.35 & 6.5000 & 7.3303 & 1.3483 & 0.3041 & 0.4100 & 0.4100 & 0.4333 & $* * * *$ & 0.0000 \\
\hline 0.40 & 6.4000 & 7.4617 & 1.4900 & 0.0000 & $* * * *$ & 0.0000 & $* * * *$ & 0.4267 & 1.0000 \\
\hline \multicolumn{10}{|c|}{ (b) Peer Effect: $\rho=0.5$} \\
\hline \multicolumn{10}{|c|}{ Community 1} \\
\hline 0.00 & 3.4000 & 4.3009 & 0.5450 & 0.5325 & 0.2523 & 0.3109 & 0.2048 & 0.5333 & 0.0667 \\
\hline 0.05 & 3.7000 & 4.5185 & 0.5517 & 0.5470 & 0.2689 & 0.3772 & 0.1917 & 0.4666 & 0.2000 \\
\hline 0.10 & 4.0000 & 4.8531 & 0.6175 & 0.4671 & 0.2658 & 0.4326 & 0.1633 & 0.4733 & 0.3333 \\
\hline 0.15 & 4.0000 & 4.7591 & 0.5783 & 0.5207 & 0.2798 & 0.4517 & 0.1733 & 0.4533 & 0.3333 \\
\hline 0.25 & 4.4000 & 4.8396 & 0.6700 & 0.0000 & $* * * *$ & 0.0000 & $* * * *$ & 0.2933 & 1.0000 \\
\hline 0.35 & 4.2000 & 4.7146 & 0.5225 & 0.0000 & $* * * *$ & 0.0000 & $* * * *$ & 0.2800 & 1.0000 \\
\hline 0.40 & 3.6000 & 4.2783 & 0.4467 & 0.0000 & $* * * *$ & 0.0000 & $* * * *$ & 0.2400 & 1.0000 \\
\hline \multicolumn{10}{|c|}{ Community 2} \\
\hline 0.00 & 4.6000 & 5.7523 & 1.0075 & 0.3976 & 0.3502 & 0.4006 & 0.3067 & $* * * *$ & 0.0000 \\
\hline 0.05 & 4.6000 & 5.6957 & 1.0192 & 0.3554 & 0.3358 & 0.3881 & 0.2905 & 0.5333 & 0.0667 \\
\hline 0.10 & 4.7549 & 5.7627 & 1.0658 & 0.3377 & 0.3439 & 0.4337 & 0.2727 & 0.5333 & 0.1699 \\
\hline 0.15 & 4.8000 & 5.8057 & 1.0325 & 0.3449 & 0.3431 & 0.4856 & 0.2424 & 0.5333 & 0.2667 \\
\hline 0.25 & 4.9981 & 5.9834 & 0.8675 & 0.4486 & 0.3689 & 0.5838 & 0.2331 & 0.5333 & 0.3333 \\
\hline 0.35 & 5.5000 & 6.0663 & 0.9508 & 0.0000 & $* * * *$ & 0.0000 & $* * * *$ & 0.3666 & 1.0000 \\
\hline 0.40 & 5.1000 & 5.9163 & 0.8342 & 0.0000 & $* * * *$ & 0.0000 & $* * * *$ & 0.3400 & 1.0000 \\
\hline \multicolumn{10}{|c|}{ Community 3} \\
\hline 0.00 & 7.0000 & 8.2684 & 1.7683 & 0.2861 & 0.4859 & 0.5060 & 0.4667 & $* * * *$ & 0.0000 \\
\hline 0.05 & 6.7000 & 8.1045 & 1.7467 & 0.2930 & 0.4781 & 0.5118 & 0.4467 & $* * * *$ & 0.0000 \\
\hline 0.10 & 6.2451 & 7.7803 & 1.7117 & 0.2693 & 0.4381 & 0.4610 & 0.4163 & $* * * *$ & 0.0000 \\
\hline 0.15 & 6.2000 & 7.7313 & 1.6833 & 0.2730 & 0.4359 & 0.4596 & 0.4133 & $* * * *$ & 0.0000 \\
\hline 0.25 & 5.6019 & 7.1411 & 1.4167 & 0.3153 & 0.4163 & 0.4786 & 0.3620 & 0.5333 & 0.0667 \\
\hline 0.35 & 5.3000 & 6.8832 & 1.1833 & 0.3505 & 0.4035 & 0.5655 & 0.2879 & 0.5333 & 0.2667 \\
\hline 0.40 & 6.3000 & 7.4700 & 1.3767 & 0.0000 & $* * * *$ & 0.0000 & $* * * *$ & 0.4200 & 1.0000 \\
\hline
\end{tabular}




\section{TABLE 6}

\section{Equilibria with Different Levels of Vouchers and Full State Funding Peer Effect: $\rho=0.5$}

\begin{tabular}{|c|c|c|c|c|c|c|c|c|c|}
\hline Voucher & Income & Wealth & Property & State. Tax & School & LPSpend & LPeer & PrPeer & \%Private \\
\hline \multicolumn{10}{|c|}{ Community 1} \\
\hline 0.00 & 2.9941 & 3.9079 & 0.3783 & 0.0779 & 0.2791 & 0.3896 & 0.1996 & $* * * *$ & 0.0000 \\
\hline 0.05 & 3.4861 & 4.2380 & 0.4100 & 0.0779 & 0.2882 & 0.3984 & 0.2109 & 0.5333 & 0.0667 \\
\hline 0.10 & 4.3000 & 4.8292 & 0.4350 & 0.0777 & 0.2832 & 0.4373 & 0.1833 & 0.4933 & 0.3333 \\
\hline 0.15 & 4.2000 & 4.7719 & 0.4817 & 0.0776 & 0.2902 & 0.4592 & 0.1833 & 0.4734 & 0.3333 \\
\hline 0.20 & 4.0500 & 4.6692 & 0.4643 & 0.0772 & 0.2976 & 0.4965 & 0.1783 & 0.4534 & 0.3333 \\
\hline 0.25 & 4.1000 & 4.7040 & 0.5050 & 0.0771 & 0.3014 & 0.4954 & 0.1833 & 0.4534 & 0.3333 \\
\hline 0.30 & 4.0000 & 4.6393 & 0.4783 & 0.0768 & 0.2811 & 0.5081 & 0.1556 & 0.4333 & 0.4000 \\
\hline 0.35 & 4.6000 & 5.0357 & 0.4967 & 0.0754 & 0.2794 & 0.5853 & 0.1333 & 0.3933 & 0.6667 \\
\hline 0.40 & 3.8000 & 4.5959 & 0.5317 & 0.0000 & $* * * *$ & 0.0000 & $* * * *$ & 0.2533 & 1.0000 \\
\hline \multicolumn{10}{|c|}{ Community 2} \\
\hline 0.00 & 5.5059 & 6.3283 & 0.9550 & 0.0779 & 0.3762 & 0.3896 & 0.3671 & $* * * *$ & 0.0000 \\
\hline 0.05 & 4.9804 & 6.0028 & 0.9617 & 0.0779 & 0.3673 & 0.3984 & 0.3320 & $* * * *$ & 0.0000 \\
\hline 0.10 & 4.7500 & 5.9512 & 1.0017 & 0.0777 & 0.3721 & 0.4373 & 0.3167 & $* * * *$ & 0.0000 \\
\hline 0.15 & 4.5000 & 5.6199 & 0.9633 & 0.0776 & 0.3483 & 0.4592 & 0.2641 & 0.5333 & 0.1333 \\
\hline 0.20 & 5.0500 & 5.8928 & 0.9467 & 0.0772 & 0.3440 & 0.4965 & 0.2383 & 0.5333 & 0.3333 \\
\hline 0.25 & 4.9000 & 5.8469 & 0.9450 & 0.0771 & 0.3326 & 0.4954 & 0.2233 & 0.5333 & 0.3333 \\
\hline 0.30 & 5.2000 & 5.9431 & 0.9667 & 0.0768 & 0.3588 & 0.5081 & 0.2533 & 0.5333 & 0.3333 \\
\hline 0.35 & 4.9000 & 5.7241 & 0.9633 & 0.0754 & 0.3615 & 0.5853 & 0.2233 & 0.5333 & 0.3333 \\
\hline 0.40 & 4.9598 & 5.9391 & 0.9533 & 0.0000 & $* * * *$ & 0.0000 & $* * * *$ & 0.3307 & 1.0000 \\
\hline \multicolumn{10}{|c|}{ Community 3} \\
\hline 0.00 & 6.5000 & 7.7191 & 1.6175 & 0.0779 & 0.4124 & 0.3896 & 0.4333 & $* * * *$ & 0.0000 \\
\hline 0.05 & 6.5335 & 7.7646 & 1.6283 & 0.0779 & 0.4144 & 0.3984 & 0.4333 & $* * * *$ & 0.0000 \\
\hline 0.10 & 5.9500 & 7.3131 & 1.6550 & 0.0779 & 0.4165 & 0.4373 & 0.3967 & $* * * *$ & 0.0000 \\
\hline 0.15 & 6.3000 & 7.7572 & 1.6983 & 0.0776 & 0.4392 & 0.4592 & 0.4200 & $* * * *$ & 0.0000 \\
\hline 0.20 & 5.9000 & 7.5305 & 1.6700 & 0.0772 & 0.4419 & 0.4965 & 0.3933 & $* * * *$ & 0.0000 \\
\hline 0.25 & 6.0000 & 7.5185 & 1.6833 & 0.0771 & 0.4451 & 0.4954 & 0.4000 & $* * * *$ & 0.0000 \\
\hline 0.30 & 5.8000 & 7.5185 & 1.6500 & 0.0768 & 0.4432 & 0.5081 & 0.3867 & $* * * *$ & 0.0000 \\
\hline 0.35 & 5.5000 & 7.3229 & 1.6150 & 0.0754 & 0.4557 & 0.5853 & 0.3548 & 0.5333 & 0.0667 \\
\hline 0.40 & 6.2402 & 7.4940 & 1.5383 & 0.0000 & $* * * *$ & 0.0000 & $* * * *$ & 0.4106 & 1.0000 \\
\hline
\end{tabular}


TABLE 7

Equilibria with Different Levels of Foundation Grants

\begin{tabular}{|c|c|c|c|c|c|c|c|c|c|}
\hline Grant Level & Income & Wealth & Property & Prop. Tax & School & LPSpend & LPeer & PrPeer & \%Private \\
\hline \multicolumn{10}{|c|}{ (a) Peer Effect: $\rho=0.00$} \\
\hline \multicolumn{10}{|c|}{ Community 1} \\
\hline 0.00 & 3.3000 & 4.3900 & 0.6550 & 0.4247 & 0.2782 & 0.2782 & 0.2200 & $* * * *$ & 0.0000 \\
\hline 0.10 & 3.4000 & 4.3793 & 0.6769 & 0.2462 & 0.2667 & 0.2667 & 0.2267 & $* * * *$ & 0.0000 \\
\hline 0.20 & 3.4000 & 4.3871 & 0.6696 & 0.1030 & 0.2690 & 0.2690 & 0.2267 & $* * * *$ & 0.0000 \\
\hline 0.30 & 3.3759 & 4.3455 & 0.6684 & 0.0000 & 0.3000 & 0.3000 & 0.2251 & $* * * *$ & 0.0000 \\
\hline 0.40 & 3.6000 & 4.5995 & 0.6575 & 0.0000 & 0.4000 & 0.4000 & 0.2400 & $* * * *$ & 0.0000 \\
\hline 0.50 & 3.6000 & 4.5997 & 0.6750 & 0.0000 & 0.5000 & 0.5000 & 0.2400 & $* * * *$ & 0.0000 \\
\hline \multicolumn{10}{|c|}{ Community 2} \\
\hline 0.00 & 5.2000 & 6.3027 & 1.0250 & 0.3880 & 0.3977 & 0.3977 & 0.3467 & $* * * *$ & 0.0000 \\
\hline 0.10 & 5.3000 & 6.3685 & 1.0274 & 0.3093 & 0.4178 & 0.4178 & 0.3533 & $* * * *$ & 0.0000 \\
\hline 0.20 & 5.3715 & 6.3792 & 1.0189 & 0.2307 & 0.4351 & 0.4351 & 0.3581 & $* * * *$ & 0.0000 \\
\hline 0.30 & 5.5250 & 6.4068 & 1.0116 & 0.1456 & 0.4473 & 0.4473 & 0.3683 & $* * * *$ & 0.0000 \\
\hline 0.40 & 5.2000 & 6.1223 & 1.0167 & 0.0000 & 0.4000 & 0.4000 & 0.3467 & $* * * *$ & 0.0000 \\
\hline 0.50 & 5.0000 & 6.0533 & 1.0283 & 0.0000 & 0.5000 & 0.5000 & 0.3333 & $* * * *$ & 0.0000 \\
\hline \multicolumn{10}{|c|}{ Community 3} \\
\hline 0.00 & 6.5000 & 7.5573 & 1.5700 & 0.2706 & 0.4248 & 0.4248 & 0.4333 & $* * * *$ & 0.0000 \\
\hline 0.10 & 6.3000 & 7.5119 & 1.5554 & 0.2053 & 0.4194 & 0.4194 & 0.4200 & $* * * *$ & 0.0000 \\
\hline 0.20 & 6.2285 & 7.4656 & 1.5432 & 0.1402 & 0.4163 & 0.4163 & 0.4152 & $* * * *$ & 0.0000 \\
\hline 0.30 & 6.1000 & 7.4625 & 1.5347 & 0.0755 & 0.4158 & 0.4158 & 0.4067 & $* * * *$ & 0.0000 \\
\hline 0.40 & 6.2000 & 7.4873 & 1.5350 & 0.0168 & 0.4259 & 0.5259 & 0.4133 & $* * * *$ & 0.0000 \\
\hline 0.50 & 6.4000 & 7.5853 & 1.5350 & 0.0000 & 0.5000 & 0.5000 & 0.4267 & $* * * *$ & 0.0000 \\
\hline
\end{tabular}

Community 1

\begin{tabular}{|c|c|c|c|c|c|c|c|c|c|}
\hline 0.00 & 3.4000 & 4.3009 & 0.5450 & 0.5325 & 0.2523 & 0.3109 & 0.2048 & 0.5333 & 0.0667 \\
\hline 0.10 & 3.4000 & 4.2465 & 0.5217 & 0.3713 & 0.2524 & 0.3122 & 0.2048 & 0.5333 & 0.0667 \\
\hline 0.20 & 3.7000 & 4.3725 & 0.4850 & 0.2182 & 0.2417 & 0.3443 & 0.1697 & 0.4583 & 0.2667 \\
\hline 0.30 & 3.0000 & 4.0100 & 0.4833 & 0.1040 & 0.2647 & 0.3503 & 0.2000 & $* * * *$ & 0.0000 \\
\hline 0.40 & 3.1000 & 4.0140 & 0.4408 & 0.0000 & 0.2875 & 0.4000 & 0.2067 & $* * * *$ & 0.0000 \\
\hline 0.50 & 3.2000 & 4.0520 & 0.4817 & 0.0000 & 0.3266 & 0.5000 & 0.2133 & $* * * *$ & 0.0000 \\
\hline \multicolumn{10}{|c|}{ Community 2} \\
\hline 0.00 & 4.6000 & 5.7523 & 1.0075 & 0.3976 & 0.3505 & 0.4006 & 0.3067 & $* * * *$ & 0.0000 \\
\hline 0.10 & 4.6000 & 5.7451 & 0.9950 & 0.3095 & 0.3525 & 0.4079 & 0.3067 & $* * * *$ & 0.0000 \\
\hline 0.20 & 5.1000 & 6.1235 & 1.0250 & 0.2132 & 0.3772 & 0.4185 & 0.3400 & $* * * *$ & 0.0000 \\
\hline 0.30 & 4.9000 & 5.8790 & 1.0133 & 0.1061 & 0.3649 & 0.4075 & 0.3267 & $* * * *$ & 0.0000 \\
\hline 0.40 & 5.4000 & 6.2108 & 1.0133 & 0.0514 & 0.4034 & 0.4521 & 0.3600 & $* * * *$ & 0.0000 \\
\hline 0.50 & 5.1000 & 6.2327 & 1.0300 & 0.0000 & 0.4123 & 0.5000 & 0.3400 & $* * * *$ & 0.0000 \\
\hline \multicolumn{10}{|c|}{ Community 3} \\
\hline 0.00 & 7.0000 & 8.2684 & 1.7683 & 0.2861 & 0.4859 & 0.5060 & 0.4667 & $* * * *$ & 0.0000 \\
\hline 0.10 & 7.0000 & 8.2704 & 1.7483 & 0.2357 & 0.4877 & 0.5120 & 0.4667 & $* * * *$ & 0.0000 \\
\hline 0.20 & 6.2000 & 7.7044 & 1.6900 & 0.1779 & 0.4549 & 0.5006 & 0.4133 & $* * * *$ & 0.0000 \\
\hline 0.30 & 7.1000 & 8.3610 & 1.7533 & 0.1133 & 0.4858 & 0.4986 & 0.4733 & $* * * *$ & 0.0000 \\
\hline 0.40 & 6.5000 & 7.9102 & 1.6808 & 0.0475 & 0.4560 & 0.4799 & 0.4333 & $* * * *$ & 0.0000 \\
\hline 0.50 & 6.7000 & 7.9237 & 1.6967 & 0.0000 & 0.4726 & 0.5000 & 0.4467 & $* * * *$ & 0.0000 \\
\hline
\end{tabular}

(b) Peer Effect: $\rho=\mathbf{0 . 5 0}$ 
TABLE 8

Equilibria with Different Levels of Vouchers and Foundation Grant $=0.40$

Peer Effect: $p=0.5$

\begin{tabular}{|c|c|c|c|c|c|c|c|c|c|}
\hline Voucher & Income & Wealth & Property & Prop. Tax & School & LPSpend & LPeer & PrPeer & $\%$ Private \\
\hline \multicolumn{10}{|c|}{ Community 1} \\
\hline $0.00-0.05$ & 3.1000 & 4.0140 & 0.4408 & 0.0000 & 0.2875 & 0.4000 & 0.2067 & $* * * *$ & 0.0000 \\
\hline 0.10 & 4.1000 & 4.7078 & 0.5125 & 0.0000 & 0.2708 & 0.4000 & 0.1833 & 0.4534 & 0.3333 \\
\hline 0.20 & 4.1000 & 4.7489 & 0.5142 & 0.0000 & 0.2582 & 0.4000 & 0.1667 & 0.4333 & 0.4000 \\
\hline 0.25 & 4.1000 & 4.8132 & 0.5575 & 0.0000 & 0.2309 & 0.4000 & 0.1333 & 0.3433 & 0.6667 \\
\hline 0.35 & 3.8000 & 4.6303 & 0.5642 & 0.0000 & 0.2309 & 0.4000 & 0.1333 & 0.3333 & 0.6000 \\
\hline 0.45 & 3.4000 & 4.4973 & 0.5658 & 0.0000 & $* * * *$ & 0.0000 & $* * * *$ & 0.2267 & I. .0000 \\
\hline \multicolumn{10}{|c|}{ Community 2} \\
\hline $0.00-0.05$ & 5.4000 & 6.2108 & 1.0133 & 0.0514 & 0.4034 & 0.4521 & 0.3600 & $* * * *$ & 0.0000 \\
\hline 0.10 & 4.9000 & 5.8227 & 0.9550 & 0.0000 & 0.2989 & 0.4000 & 0.2233 & 0.5333 & 0.3333 \\
\hline 0.20 & 5.2000 & 5.9564 & 0.9683 & 0.0000 & 0.3055 & 0.4000 & 0.2333 & 0.5167 & 0.4000 \\
\hline 0.25 & 5.2000 & 6.0685 & 0.9900 & 0.0000 & 0.2633 & 0.4000 & 0.1733 & 0.4333 & 0.6667 \\
\hline 0.35 & 5.1000 & 5.9540 & 0.9750 & 0.0000 & 0.2309 & 0.4000 & 0.1333 & 0.3718 & 0.8667 \\
\hline 0.45 & 5.3500 & 6.0638 & 0.9733 & 0.0000 & $* * * *$ & 0.0000 & $* * * *$ & 0.3566 & 1.0000 \\
\hline \multicolumn{10}{|c|}{ Community 3} \\
\hline $0.00-0.05$ & 6.5000 & 7.9102 & 1.6808 & 0.0475 & 0.4560 & 0.4799 & 0.4333 & $* * * *$ & 0.0000 \\
\hline 0.10 & 6.0000 & 7.6412 & 1.7042 & 0.0255 & 0.4211 & 0.4434 & 0.4000 & $* * * *$ & 0.0000 \\
\hline 0.20 & 5.7000 & 7.4297 & 1.6525 & 0.0235 & 0.4083 & 0.4388 & 0.3800 & $* * * *$ & 0.0000 \\
\hline 0.25 & 5.7000 & 7.2450 & 1.5792 & 0.0000 & 0.2944 & 0.4000 & 0.2167 & 0.4888 & 0.6000 \\
\hline 0.35 & 6.1000 & 7.5023 & 1.5475 & 0.0000 & 0.2309 & 0.4000 & 0.1333 & 0.4262 & 0.9333 \\
\hline 0.45 & 6.2500 & 7.5205 & 1.5425 & 0.0000 & $* * * *$ & 0.0000 & $* * * *$ & 0.4167 & 1.0000 \\
\hline
\end{tabular}


TABLE 9

Equilibria with Different Levels of Revenue Neutral DPE

\begin{tabular}{|c|c|c|c|c|c|c|c|c|c|}
\hline$\%$ Equaliz. & Income & Wealth & Property & Prop. Tax & School & LPSpend & LPeer & PrPeer & \%Private \\
\hline \multicolumn{10}{|c|}{ (a) Peer Effect: $\rho=0$} \\
\hline \multicolumn{10}{|c|}{ Community 1} \\
\hline None & 3.3000 & 4.3900 & 0.6550 & 0.4247 & 0.2782 & 0.2782 & 0.2200 & $* * * *$ & 0.0000 \\
\hline $20 \%$ & 3.7200 & 4.5976 & 0.6874 & 0.4138 & 0.3259 & 0.3259 & 0.2480 & $* * * *$ & 0.0000 \\
\hline $10 \%$ & 3.8000 & 4.7183 & 0.7318 & 0.3960 & 0.3707 & 0.3707 & 0.2533 & $* * * *$ & 0.0000 \\
\hline Full & 3.8000 & 4.7165 & 0.7462 & 0.3916 & 0.4073 & 0.4073 & 0.2533 & $* * * *$ & 0.0000 \\
\hline \multicolumn{10}{|c|}{ Community 2} \\
\hline None & 5.2000 & 6.3027 & 1.0250 & 0.3880 & 0.3977 & 0.3977 & 0.3467 & $* * * *$ & 0.0000 \\
\hline $20 \%$ & 5.0800 & 6.1770 & 1.0202 & 0.3749 & 0.3936 & 0.3936 & 0.3387 & $* * * *$ & 0.0000 \\
\hline $10 \%$ & 5.0000 & 6.1168 & 1.0370 & 0.3660 & 0.3854 & 0.3854 & 0.3333 & $* * * *$ & 0.0000 \\
\hline Full & 4.9000 & 6.1059 & 1.0322 & 0.3741 & 0.3891 & 0.3891 & 0.3267 & $* * * *$ & 0.0000 \\
\hline \multicolumn{10}{|c|}{ Community 3} \\
\hline None & 6.5000 & 7.5573 & 1.5700 & 0.2706 & 0.4248 & 0.4248 & 0.4333 & $* * * *$ & 0.0000 \\
\hline $20 \%$ & 6.2000 & 7.4310 & 1.4980 & 0.2830 & 0.3713 & 0.3713 & 0.4133 & $* * * *$ & 0.0000 \\
\hline $10 \%$ & 6.2000 & 7.4016 & 1.4680 & 0.2915 & 0.3411 & 0.3411 & 0.4133 & $* * * *$ & 0.0000 \\
\hline Fuلl & 6.3000 & 7,3916 & 1.4356 & 0.2985 & 0.3104 & 0.3104 & 0.4200 & $* * * *$ & 0.0000 \\
\hline \multicolumn{10}{|c|}{ (b) Peer Effect: $\rho=0.5$} \\
\hline \multicolumn{10}{|c|}{ Community 1} \\
\hline None & 3.4000 & 4.3009 & 0.5450 & 0.5325 & 0.2523 & 0.3109 & 0.2048 & 0.5333 & 0.0667 \\
\hline $20 \%$ & 3.3000 & 4.0833 & 0.5933 & 0.4654 & 0.2831 & 0.3644 & 0.2200 & $* * * *$ & 0.0000 \\
\hline $10 \%$ & 3.3000 & 4.3457 & 0.6183 & 0.5081 & 0.3165 & 0.4553 & 0.2200 & $* * * *$ & 0.0000 \\
\hline Full & 3.3000 & 4.3312 & 0.6717 & $0.5 I 46$ & 0.3429 & 0.5344 & 0.2200 & $* * * *$ & 0.0000 \\
\hline \multicolumn{10}{|c|}{ Community 2} \\
\hline None & 4.6000 & 5.7523 & 1.0075 & 0.3976 & 0.3505 & 0.4006 & 0.3067 & $* * * *$ & 0.0000 \\
\hline $20 \%$ & 5.4000 & 6.4597 & 1.0483 & 0.4366 & 0.4051 & 0.4558 & 0.3600 & $* * * *$ & 0.0000 \\
\hline $10 \%$ & 5.4000 & 6.3573 & 1.0400 & 0.4429 & 0.4010 & 0.4466 & 0.3600 & $* * * *$ & 0.0000 \\
\hline Full & 5.1039 & 6.3125 & 1.0450 & 0.4695 & 0.4073 & 0.4876 & 0.3403 & $* * * *$ & 0.0000 \\
\hline \multicolumn{10}{|c|}{ Community 3} \\
\hline None & 7.0000 & 8.2684 & 1.7683 & 0.2861 & 0.4859 & 0.5060 & 0.4667 & $* * * *$ & 0.0000 \\
\hline $20 \%$ & 6.3000 & 7.7087 & 1.6100 & 0.2830 & 0.3938 & 0.3693 & 0.4200 & $* * * *$ & 0.0000 \\
\hline $10 \%$ & 6.3000 & 7.5070 & 1.5517 & 0.2945 & 0.3722 & 0.3299 & 0.4200 & $* * * *$ & 0.0000 \\
\hline Full & 6.5961 & 7.6229 & 1.5500 & 0.3628 & 0.4070 & 0.3768 & 0.4397 & $* * * *$ & 0.0000 \\
\hline
\end{tabular}


TABLE 10

Equilibria with Different Levels of Vouchers and Full Revenue Neutral DPE Peer Effect: $\rho=0.5$

\begin{tabular}{|c|c|c|c|c|c|c|c|c|c|}
\hline Voucher & Income & Wealth & Property & Prop. Tax & School & LPSpend & LPeer & PrPeer & $\%$ Private \\
\hline \multicolumn{10}{|c|}{ Community 1} \\
\hline $0.00-0.15$ & 3.3000 & 4.3312 & 0.6717 & 0.5146 & 0.3429 & 0.5344 & 0.2200 & 0.0000 & 0.0000 \\
\hline 0.20 & 3.3616 & 4.3860 & 0.6933 & 0.4852 & 0.3342 & 0.5530 & 0.2020 & 0.5333 & 0.0667 \\
\hline 0.30 & 3.7000 & 4.5153 & 0.5217 & 0.6104 & 0.3219 & 0.5979 & 0.1733 & 0.3934 & 0.3333 \\
\hline 0.35 & 3.6634 & 4.5041 & 0.5250 & 0.5243 & 0.3262 & 0.6137 & 0.1733 & 0.3861 & 0.3333 \\
\hline 0.45 & 3.6691 & 4.5333 & 0.5283 & 0.6147 & 0.3261 & 0.6135 & 0.1733 & 0.3872 & 0.3333 \\
\hline 0.50 & 3.7000 & 4.4384 & 0.4953 & 0.0000 & $* * * *$ & 0.0000 & $* * * *$ & 0.2467 & 1.0000 \\
\hline \multicolumn{10}{|c|}{ Community 2} \\
\hline $0.00-0.15$ & 5.1039 & 6.3125 & 1.0450 & 0.4695 & 0.4073 & 0.4876 & 0.3403 & 0.0000 & 0.0000 \\
\hline 0.20 & 5.2384 & 6.3640 & 1.0692 & 0.4539 & 0.4106 & 0.4828 & 0.3492 & 0.0000 & 0.0000 \\
\hline 0.30 & 4.8000 & 5.8711 & 0.8117 & 0.5188 & 0.3369 & 0.5083 & 0.2233 & 0.5134 & 0.3333 \\
\hline 0.35 & 4.8366 & 5.8892 & 0.8312 & 0.4760 & 0.3384 & 0.5849 & 0.1958 & 0.4672 & 0.4667 \\
\hline 0.45 & 4.8309 & 5.8785 & 0.8567 & 0.4405 & 0.3281 & 0.5496 & 0.1958 & 0.4666 & 0.4667 \\
\hline 0.50 & 4.9000 & 5.9215 & 0.8867 & 0.0000 & $* * * *$ & 0.0000 & $* * * *$ & 0.3267 & 1.0000 \\
\hline \multicolumn{10}{|c|}{ Community 3} \\
\hline $0.00-0.15$ & 6.5961 & 7.6229 & 1.5500 & 0.3628 & 0.4070 & 0.3768 & 0.4397 & $* * * *$ & 0.0000 \\
\hline 0.20 & 6.4000 & 7.5676 & 1.5583 & 0.3583 & 0.4033 & 0.3811 & 0.4267 & $* * * *$ & 0.0000 \\
\hline 0.30 & 6.5000 & 7.7276 & 1.7483 & 0.0000 & $* * * *$ & 0.0000 & $* * * *$ & 0.4333 & 1.0000 \\
\hline 0.35 & 6.5000 & 7.7500 & 1.7583 & 0.0000 & $* * * *$ & 0.0000 & $* * * *$ & 0.4333 & 1.0000 \\
\hline 0.45 & 6.5000 & 7.7673 & 1.7700 & 0.0000 & $* * * *$ & 0.0000 & $* * * *$ & 0.4333 & 1.0000 \\
\hline 0.50 & 6.4000 & 7.5000 & 1.4350 & 0.0000 & $* * * *$ & 0.0000 & $* * * *$ & 0.4267 & 1.0000 \\
\hline
\end{tabular}

